OAK RIDGE

NATIONAL LABORATORY

MANAGED BY UT-BATTELLE

FOR THE DEPARTMENT OF ENERGY

\title{
AHTR Refueling Systems and Process Description
}

\section{July 2012}

Prepared by

V. K. Varma

D. E. Holcomb

E. C. Bradley

N. M. Zaharia

E. J. Cooper

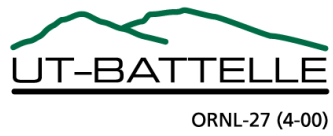




\section{DOCUMENT AVAILABILITY}

Reports produced after January 1, 1996, are generally available free via the U.S. Department of Energy (DOE) Information Bridge.

Web site http://www.osti.gov/bridge

Reports produced before January 1, 1996, may be purchased by members of the public from the following source.

National Technical Information Service

5285 Port Royal Road

Springfield, VA 22161

Telephone 703-605-6000 (1-800-553-6847)

TDD 703-487-4639

Fax 703-605-6900

E-mail info@ntis.gov

Web site http://www.ntis.gov/support/ordernowabout.htm

Reports are available to DOE employees, DOE contractors, Energy Technology Data Exchange (ETDE) representatives, and International Nuclear Information System (INIS) representatives from the following source.

Office of Scientific and Technical Information

P.O. Box 62

Oak Ridge, TN 37831

Telephone 865-576-8401

Fax 865-576-5728

E-mail reports@osti.gov

Web site http://www.osti.gov/contact.html

This report was prepared as an account of work sponsored by an agency of the United States Government. Neither the United States Government nor any agency thereof, nor any of their employees, makes any warranty, express or implied, or assumes any legal liability or responsibility for the accuracy, completeness, or usefulness of any information, apparatus, product, or process disclosed, or represents that its use would not infringe privately owned rights. Reference herein to any specific commercial product, process, or service by trade name, trademark, manufacturer, or otherwise, does not necessarily constitute or imply its endorsement, recommendation, or favoring by the United States Government or any agency thereof. The views and opinions of authors expressed herein do not necessarily state or reflect those of the United States Government or any agency thereof. 
ORNL/TM-2012/292

Fuel Cycle and Isotopes Division

\title{
AHTR REFUELING SYSTEMS AND PROCESS DESCRIPTION
}

\author{
V. K. Varma \\ D. E. Holcomb \\ E. C. Bradley \\ N. M. Zaharia \\ E. J. Cooper
}

Date Published: July 2012

Prepared by OAK RIDGE NATIONAL LABORATORY

Oak Ridge, Tennessee 37831-6283

managed by

UT-BATTELLE, LLC

for the

U.S. DEPARTMENT OF ENERGY

under contract DE-AC05-00OR22725 



\section{CONTENTS}

Page

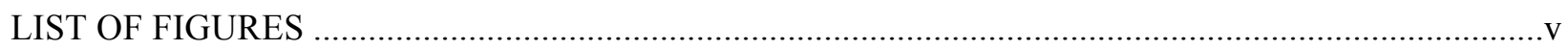

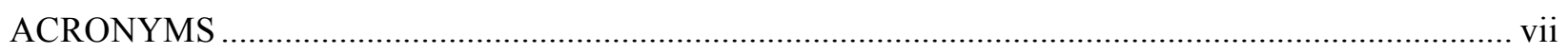

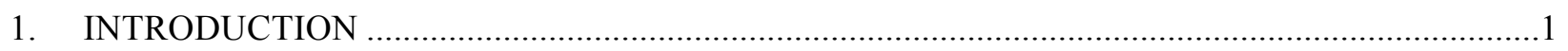

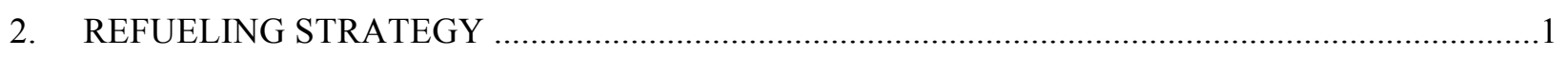

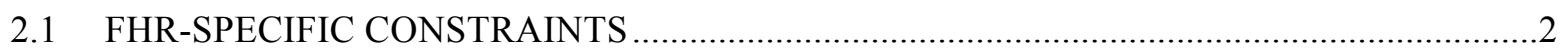

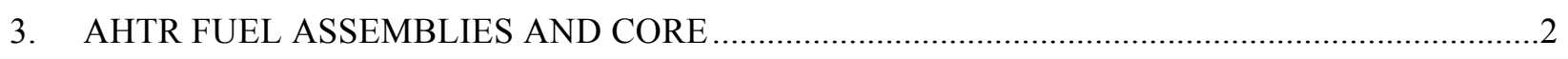

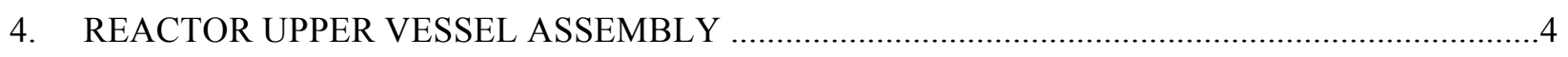

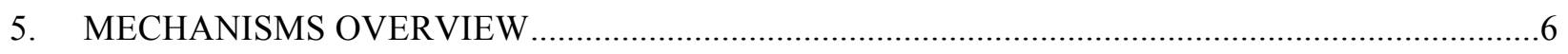

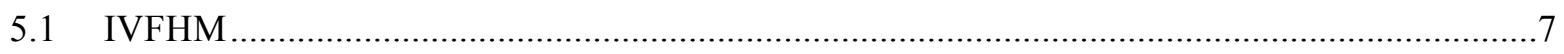

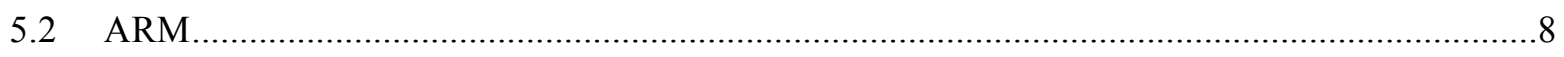

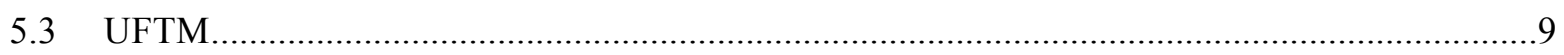

6. REFUELING PATH COMPONENTS AND STRUCTURES.................................................

6.1 NEW FUEL ASSEMBLIES AREA …............................................................................12

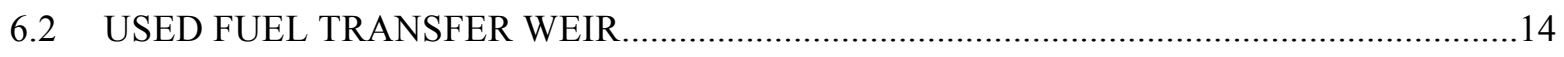

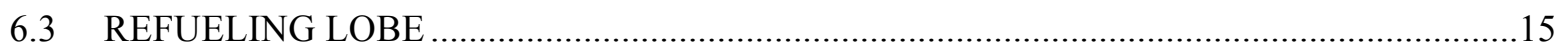

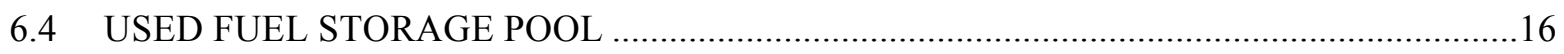

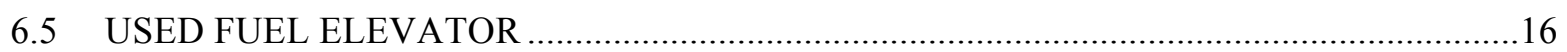

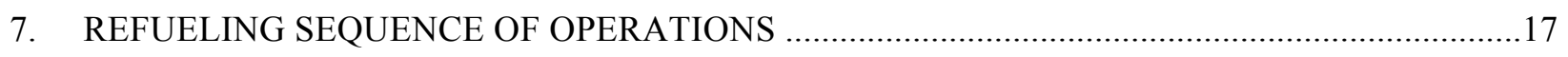

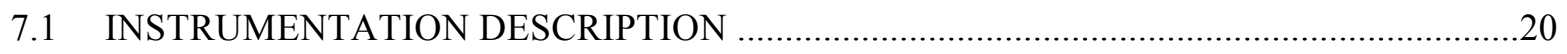

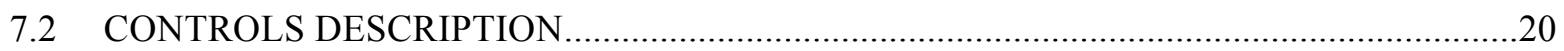

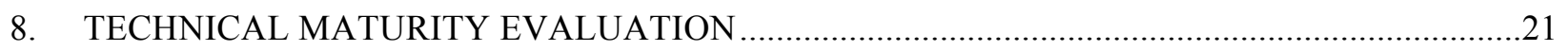

9. SUMMARY AND RECOMMENDATIONS FOR FUTURE DEVELOPMENTS ........................21

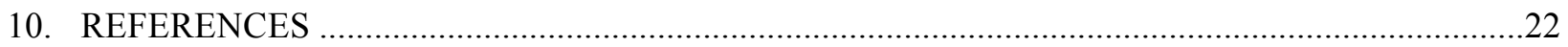





\section{LIST OF FIGURES}

Figure $\quad$ Page

1 Top view of the reactor core and vessel with an expanded view of a single fuel assembly...........

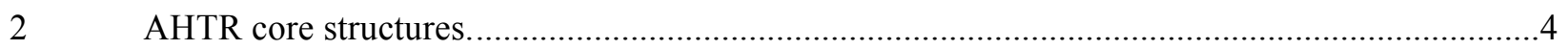

3 AHTR upper vessel components in exploded view with retracted control blade. .........................5

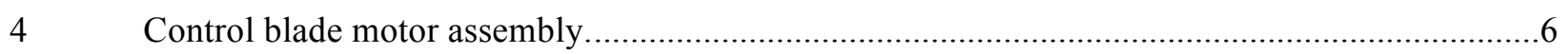

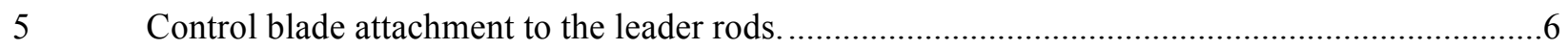

$6 \quad$ Reactor top view showing all three manipulators. ...............................................................

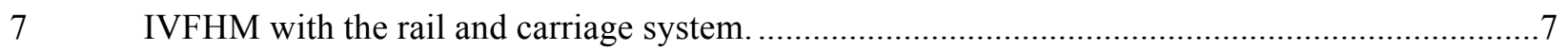

$8 \quad$ IVFHM holding a fuel assembly and close-up of the grapple. ...................................................

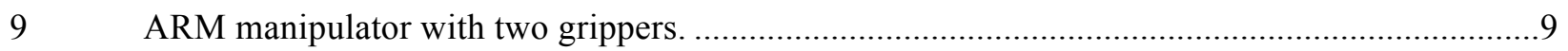

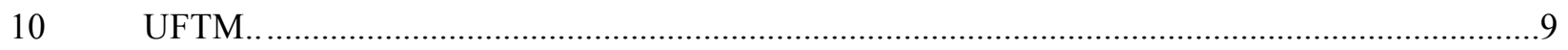

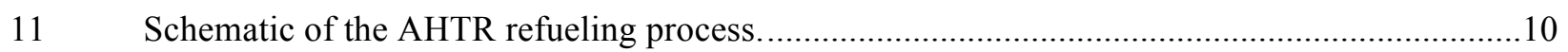

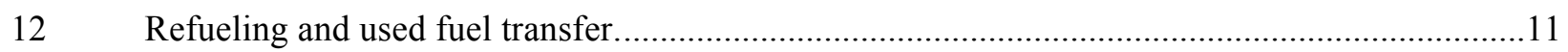

13 New fuel loading and used fuel transfer in the reactor lobe....................................................11

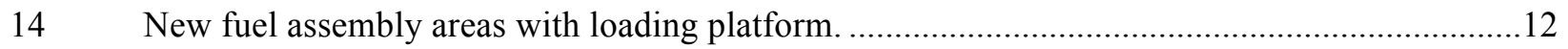

15 Seal on the loading platform at the new fuel assembly area. ..................................................13

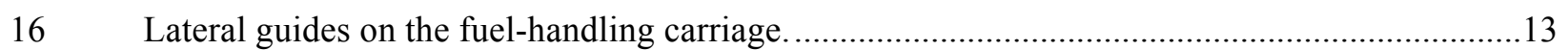

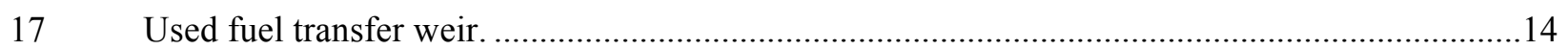

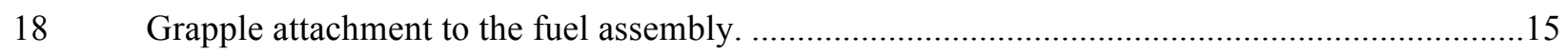

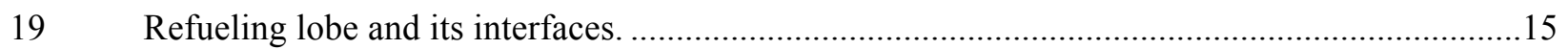

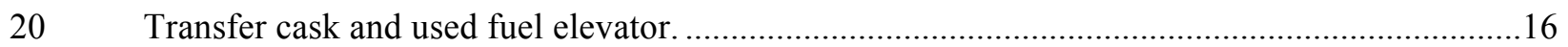

21 Upper core support plate is raised, allowing access to the fuel assemblies for refueling. ............18

22 IVFHM, ARM, and UFTM inside the reactor vessel............................................................18

23 Control blade flange with a single control blade drive mechanism retracted. ...........................19 



\section{ACRONYMS}

AHTR

ARM

C-C Composite

DRACS

FHR

FLiBe

IVFHM

LWR

NFAA

SiC-SiC Composite

SSC

UFTM
Advanced High Temperature Reactor

Annular Ring Manipulator

Carbon-Carbon Composite

Direct Reactor Auxiliary Cooling System

Fluoride salt-cooled High-temperature Reactor

Lithium Fluoride Beryllium Fluoride

In-Vessel Fuel Handling Manipulator

Light Water Reactor

New Fuel Assembly Area

Silicon Carbide-Silicon Carbide Composite

Systems, Structures, and Components

Used Fuel Transfer Manipulator 



\section{INTRODUCTION}

The Advanced High-Temperature Reactor (AHTR) is a design concept for a central station-type [1500 MW(e)] Fluoride salt-cooled High-temperature Reactor (FHR) that is currently undergoing development by Oak Ridge National Laboratory for the US. Department of Energy, Office of Nuclear Energy's Advanced Reactor Concepts program. FHRs, by definition, feature low-pressure liquid fluoride salt cooling, coated-particle fuel, a high-temperature power cycle, and fully passive decay heat rejection. The overall goal of the AHTR development program is to demonstrate the technical feasibility of FHRs as low-cost, large-size power producers while maintaining full passive safety.

The AHTR is approaching a preconceptual level of maturity. An initial integrated layout of its major systems, structures, and components (SSCs), and an initial, high-level sequence of operations necessary for constructing and operating the plant is nearing completion. An overview of the current status of the AHTR concept has been recently published [1], and a report providing a more detailed overview of the AHTR structures and mechanical systems is currently in preparation.

This report documents the refueling components and processes envisioned at this early development phase. The report is limited to the refueling aspects of the AHTR and does not include overall reactor or power plant design information. The report, however, does include a description of the materials envisioned for the various components and the instrumentation necessary to control the refueling process. The report begins with an overview of the refueling strategy. Next a mechanical description of the AHTR fuel assemblies and core is provided. The reactor vessel upper assemblies are then described. Following this the refueling path structures and the refueling mechanisms and components are described. The sequence of operations necessary to fuel and defuel the reactor is then discussed. The report concludes with a discussion of the levels of maturity of the various SSCs to provide guidance for future technology developments.

The conceptual design information presented in this report is very preliminary in nature. Significant uncertainty remains about several aspects of the process and even the radiation and mechanical performance of plate-type coated-particle fuel.

\section{REFUELING STRATEGY}

As a low-pressure system with mechanically and thermally robust fuel, most of the time-consuming, nonfuel manipulation steps required in light water reactor (LWR) refueling are avoided in the AHTR. AHTR refueling can begin immediately upon reactor shutdown, as the coolant temperature does not need to be lowered below its boiling point before opening the vessel, nor does the vessel top need to be opened, moved, and stored or the reactor cavity flooded and later drained. The mechanical manipulations to add or remove a fuel assembly are similar in an LWR and the AHTR. Thus, similar amounts of time are anticipated for fuel assembly manipulations. Current LWR practice is to move one fuel assembly roughly every $10 \mathrm{~min}$. Slightly less than 2 days would thus be required to unload the 252 fuel assemblies that comprise a full AHTR core or to unload and reload half a core. Overall, the fuel manipulation portion of an AHTR outage appears likely to be on the order of a few days.

The refueling SSCs are based upon optimizing the design around a series of generic constraints.

- Maximize plant availability_Plant availability is maximized by decreasing both refueling outage duration and frequency. 
- Minimize fuel cost—Fuel cost is minimized by decreasing the number of fuel assemblies used, decreasing the fuel uranium enrichment, and increasing the uranium discharge burnup.

- Minimize refueling system cost—Used fuel-handling systems can be large, complex, and expensive.

- Support seasonal scheduling - The value of electricity varies significantly from season to season, so being able to operate continuously through seasonal peaks is financially important.

- Minimize fuel fabrication facility requirements - Significant additional fuel costs may accrue if fuel requires enrichment beyond what can be supplied using current enrichment facilities. While beyond the licensed capability of current enrichment plants, an upper constraint of approximately $10 \%{ }^{235} \mathrm{U}$ enrichment was placed upon AHTR fuel based upon an estimate of the maximum enrichment capability of current plants with minimal modification.

- Maximize system reliability—System reliability directly impacts plant availability.

The nature of FHRs imposes additional constraints on the refueling SSCs.

\subsection{FHR-SPECIFIC CONSTRAINTS}

- Apart from the brief interval required to transfer the used fuel from the reactor vessel to the used fuel pool, fuel must be maintained within molten salt to provide decay heat removal and to provide shielding of the fuel's radioactivity to components above the salt.

- $\quad$ Refueling will take place with the salt temperature above $500^{\circ} \mathrm{C}$.

- All wetted elements must be formed from salt-compatible materials. Stainless steel 316 and Alloy N are leading candidates for salt wetted components.

- The vapor pressure of the primary salt is non-zero. $\mathrm{BeF}_{2}$ will preferentially evaporate from the salt and condense into a non-transparent polycrystalline layer upon impacting cool surfaces.

A two-batch refueling scheme with a 6-month refueling interval employing $9 \%$ enriched uranium oxycarbide coated-particle fuel is currently envisioned. The AHTR's relatively flat radial flux profile, coupled with coated-particle-fuel's high-burnup tolerance, reduces the performance advantage that could be obtained by repositioning fuel within the core (reshuffling) as part of a refueling outage. Employing a checkerboard core loading strategy that does not include fuel reshuffling minimizes the required number of fuel assembly moves, decreasing the required outage duration.

\section{AHTR FUEL ASSEMBLIES AND CORE}

The AHTR core consists of 252 fuel assemblies arranged in a hexagonal lattice with a $46.75-\mathrm{cm}$ pitch into a roughly cylindrical shape supported by upper and lower support plates. Each fuel assembly is $600 \mathrm{~cm}$ in height and has an outer apothem of $22.5 \mathrm{~cm}$. The AHTR core mechanical layout is described in more detail in Holcomb et al. [2]. A row of hexagonal replaceable reflector graphite columns, a permanent graphite reflector that includes an exterior surface boron carbide neutron absorber layer, and a $\mathrm{C}-\mathrm{C}$ composite core barrel radially surround the reactor core. The downcomer region and the reactor vessel are located radially outside of the core barrel. Figure 1 shows a top view of the AHTR core and vessel with the upper flange and upper core support plate removed, along with an expanded view of a single fuel assembly cross section. 


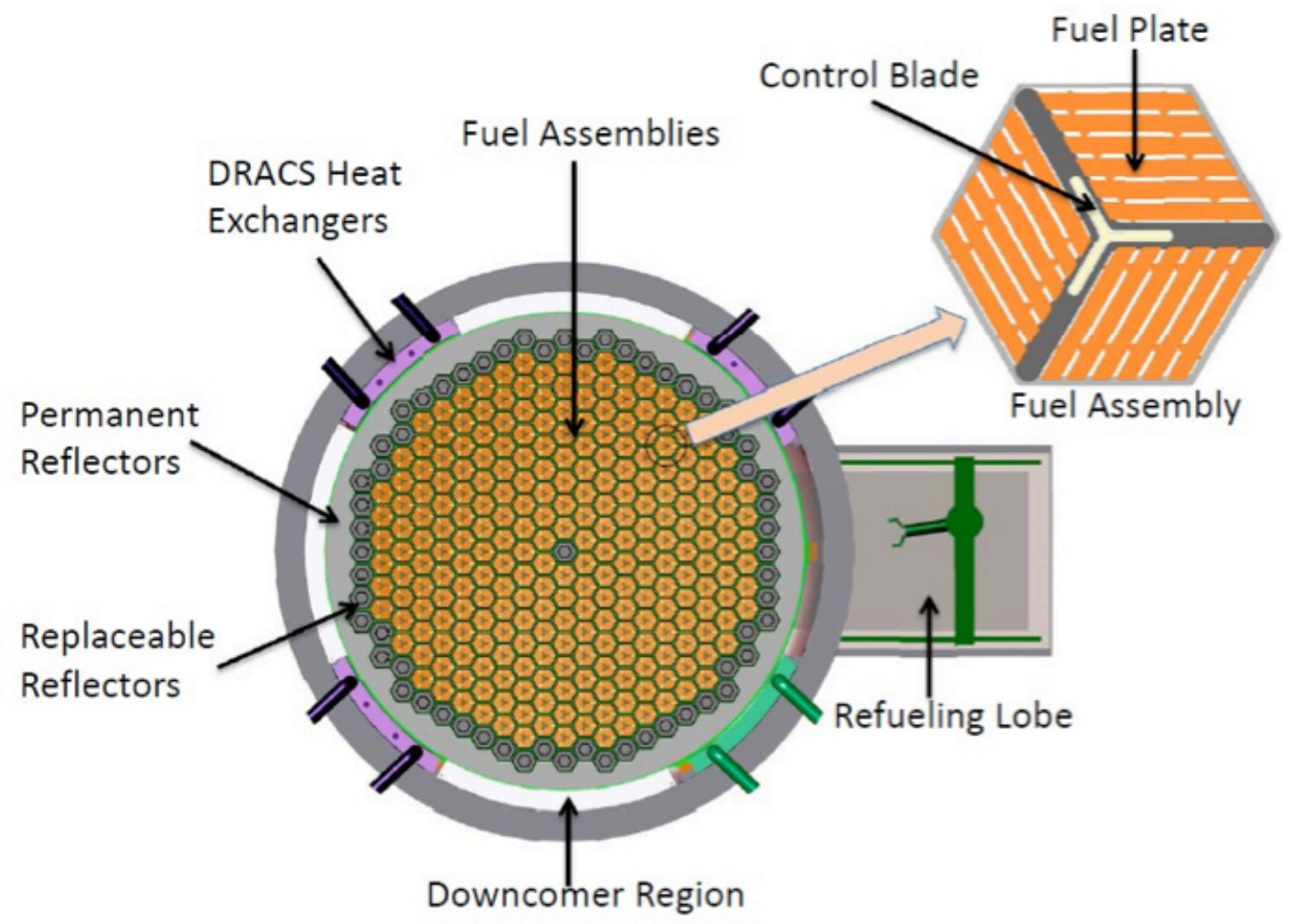

Fig. 1. Top view of the reactor core and vessel with an expanded view of a single fuel assembly.

The AHTR employs plate-type fuel held within a hexagonal structure. Flow is channelized within each fuel assembly by a carbon-carbon (C-C) composite prismatic box with 1-cm-thick walls. The interior of the hexagonal channel box is divided into three symmetric regions by a $\mathrm{Y}$-shaped structure also made of C-C composite.

Each of the three regions includes six equidistant fuel plates that are supported at one edge by the Y-shaped structure and at the other edge by the channel box. The channel boxes of two adjacent assemblies are separated by $1.7 \mathrm{~cm}$ of inter-assembly coolant. A Y-shaped control blade slot is provided at the center of each of the fuel assembly Y-shapes. Each fuel assembly has a control blade. The control blades are made from molybdenum-hafnium-carbide in eight linked sections. The individual links are joined by flexible connections to provide the flexibility necessary for the control blade to freely pass through the guide channel even if the channel has been distorted by radiation damage.

The fuel assemblies are moderately buoyant within the salt. The density of a fuel assembly $\left(\sim 1890 \mathrm{~kg} / \mathrm{m}^{3}\right)$ is slightly less than the density of salt $\left(1950 \mathrm{~kg} / \mathrm{m}^{3}\right)$. The addition of the control blades causes the fuel assemblies to sink in the primary coolant. The heavy control blades will be left in the fuel assemblies during the refueling to prevent the fuel assembly from floating upward in salt or from being lifted by the upward flow. Fuel assemblies are held down by three independent means: (1) weight of the assembly (including the control blade during refueling), (2) upper core support plate, and (3) control blade guide tube.

The fuel assemblies rest on a lower core support plate made from silicon carbide-silicon carbide (SiC-SiC) composite and are held at the top by an upper core support plate, which is also made from $\mathrm{SiC}-\mathrm{SiC}$. The lower core support plate is mounted to the reactor vessel using a sliding support structure designed to accommodate the differential thermal expansion between the metallic vessel and ceramic 
plate. The upper core support plate is a removable disk-shaped structure that aligns and holds down the individual fuel assemblies. The upper plate is attached to the vessel flange by five support rods that are raised for refueling. Figure 2 shows the reactor core structures with a front portion removed.

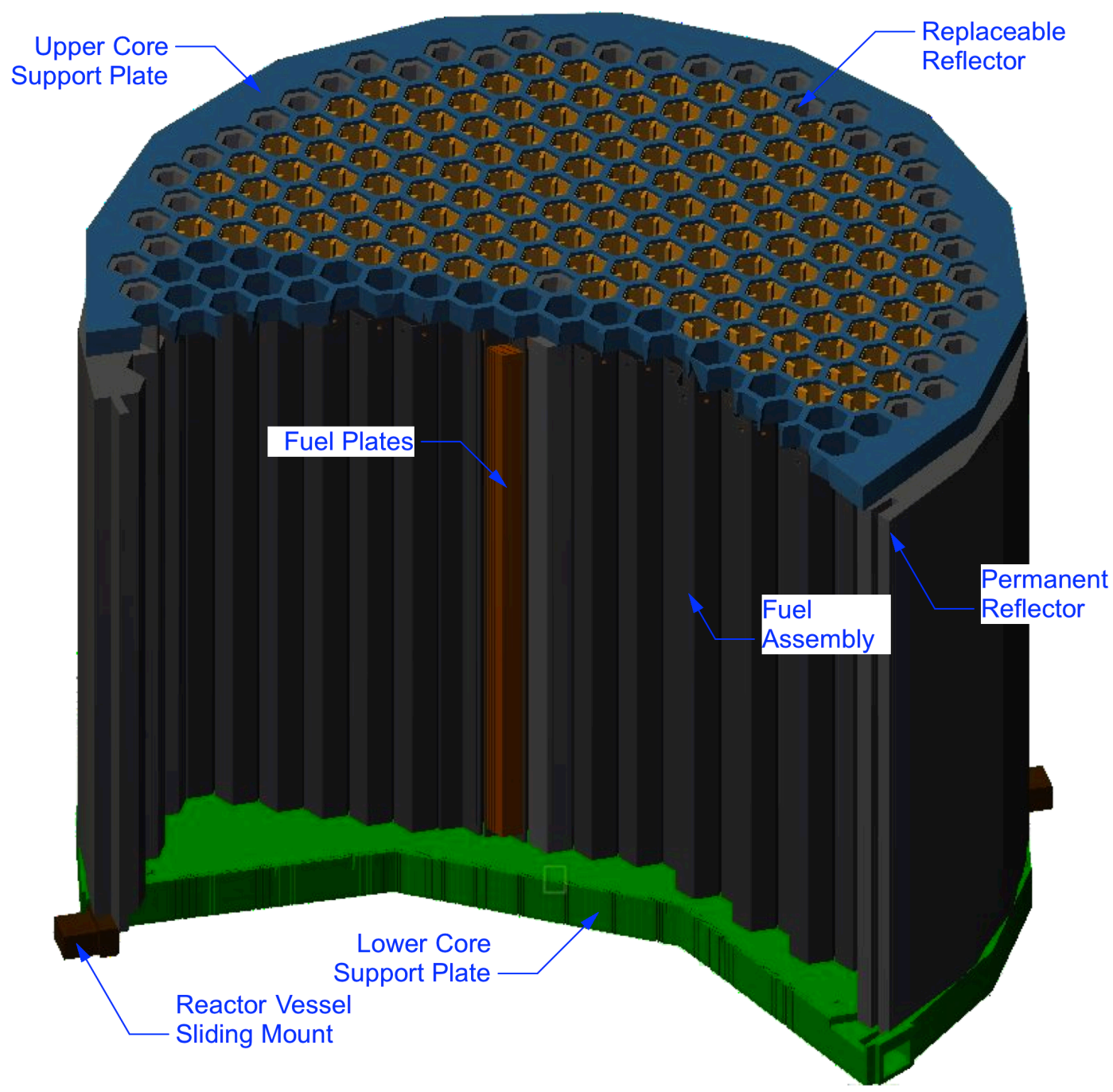

Fig. 2. AHTR core structures.

\section{REACTOR UPPER VESSEL ASSEMBLY}

For operation, the control blades are attached to a control blade leader rod. The leader rods extend from the top of the control blades to the control blade drive motors. Each control blade leader rod is encased in a control blade guide tube. The guide tubes both provide mechanical alignment for the control bladeleader rod assembly and structural support to the upper core support plate against the upwards thrust produced by upward primary coolant flow during operation. Both the guide tubes and leader rods are made from $\mathrm{SiC}-\mathrm{SiC}$ composite as they are exposed to the primary salt and to the cooler argon atmosphere above the pool.

An argon atmosphere is maintained above the top of the pool within the reactor vessel. Sufficient argon flow is provided to maintain the upper vessel flange at $\sim 250^{\circ} \mathrm{C}$ during normal operation. The flowing argon is continuously cleaned to remove any contaminating moisture or tritium that is released from the 
primary coolant. Each leader rod and guide tube extends through the upper vessel flange to a control blade drive motor assembly. The control blade drive motor assemblies are mounted on a plate located above the upper vessel flange. The control blade motor assembly plate is mounted on rails to enable lateral translation. The upper vessel flange does not provide a containment seal as both the guide tubes and leader rods pass freely through it. The upper vessel atmosphere containment is provided by an upper vessel closure that seals against the top surface of the upper vessel flange. The upper vessel closure consists of a set of tubes extending upwards to envelop the leader rods and guide tubes when in their withdrawn position. Figure 3 shows an exploded view of the upper vessel structure and control blade drive pieces.

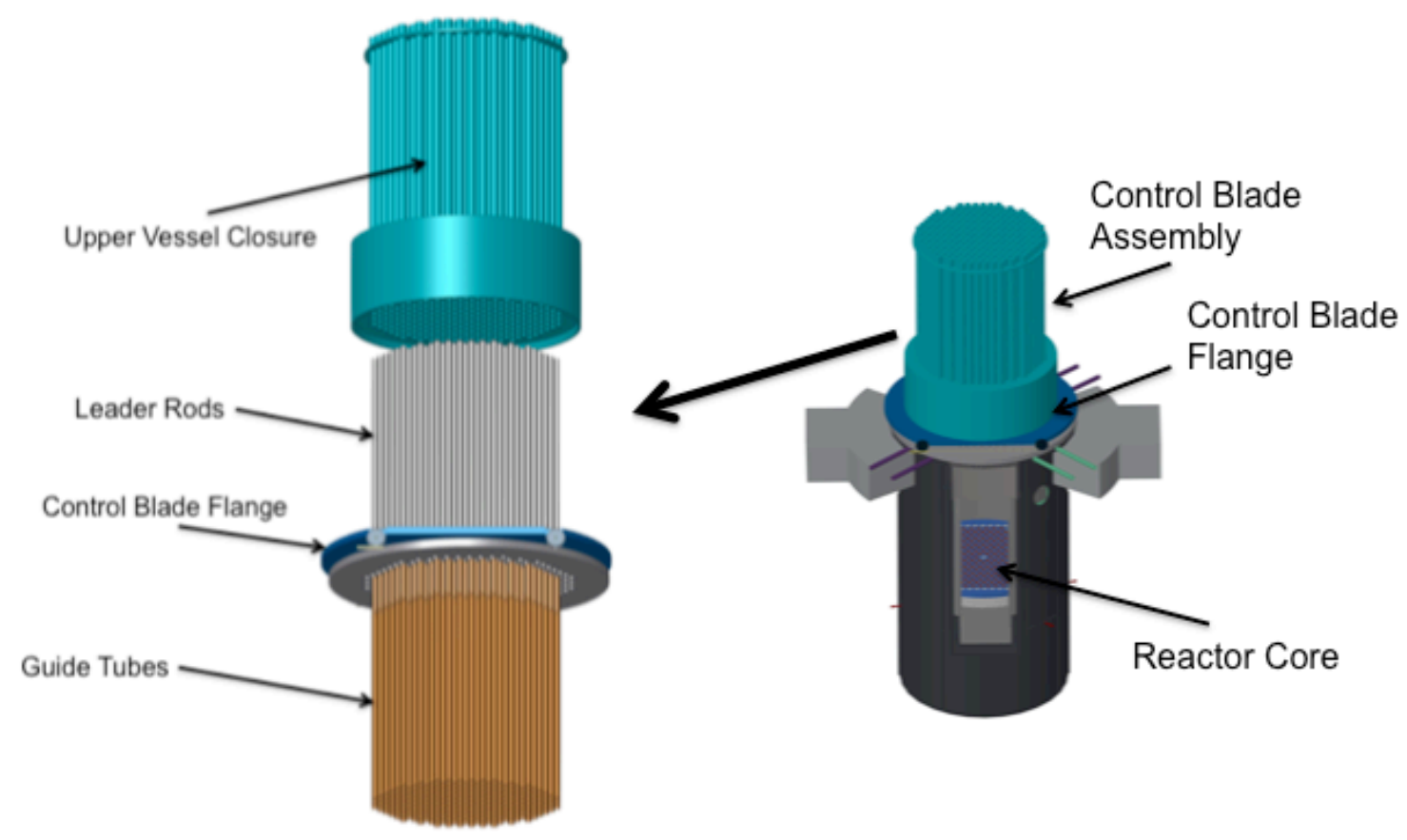

Fig. 3. AHTR upper vessel components in exploded view with retracted control blade.

Separate motors drive both the control blade leader rods and the guide tubes. The control blade leader rods slide inside the control blade guide tubes (Fig. 4). The drive motor for the leader rod is mounted on a solenoid actuator that releases the leader rods if power is lost. When the drive mechanism is disconnected, the control blades fall into the core due to gravity. The leader rods remain connected to the control blade during this scenario. Each leader rod also has a fusible link just above its end-effector. If the temperature of the coolant rises above a (yet to be determined) threshold, the fusible link melts and the control blade is released to fall into the fuel assembly. The core can still be defueled using the normal mechanisms even if the blades have been released due to the fuse melting.

Each leader rod has an end-effector that allows it to connect to its respective control blade. By rotating the leader rod, the end-effector attaches to the control blade (Fig. 5). The end-effector has a wider disk at its end to prevent detaching the leader rod unless the control blade is fully inserted into the fuel assembly. The leader rod can be raised or lowered by actuating the motor mounted to the control blade plate. 


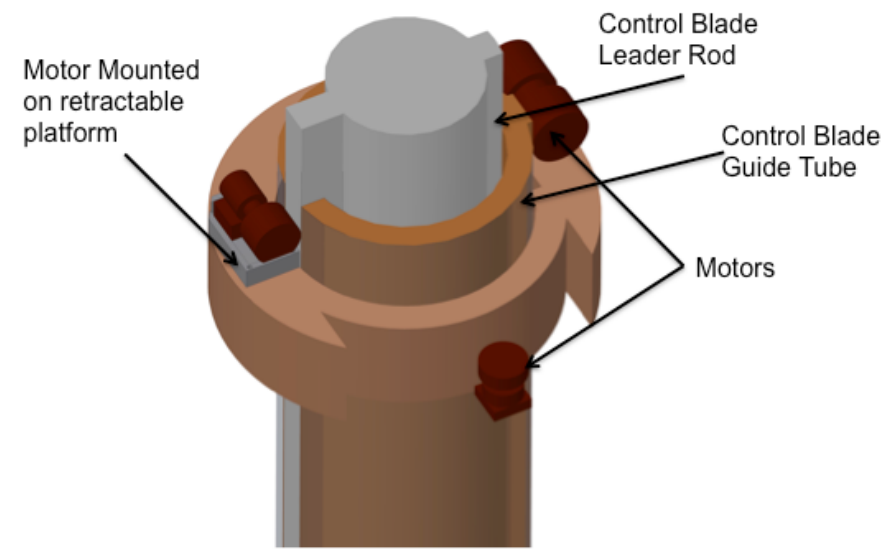

Fig. 4. Control blade motor assembly.

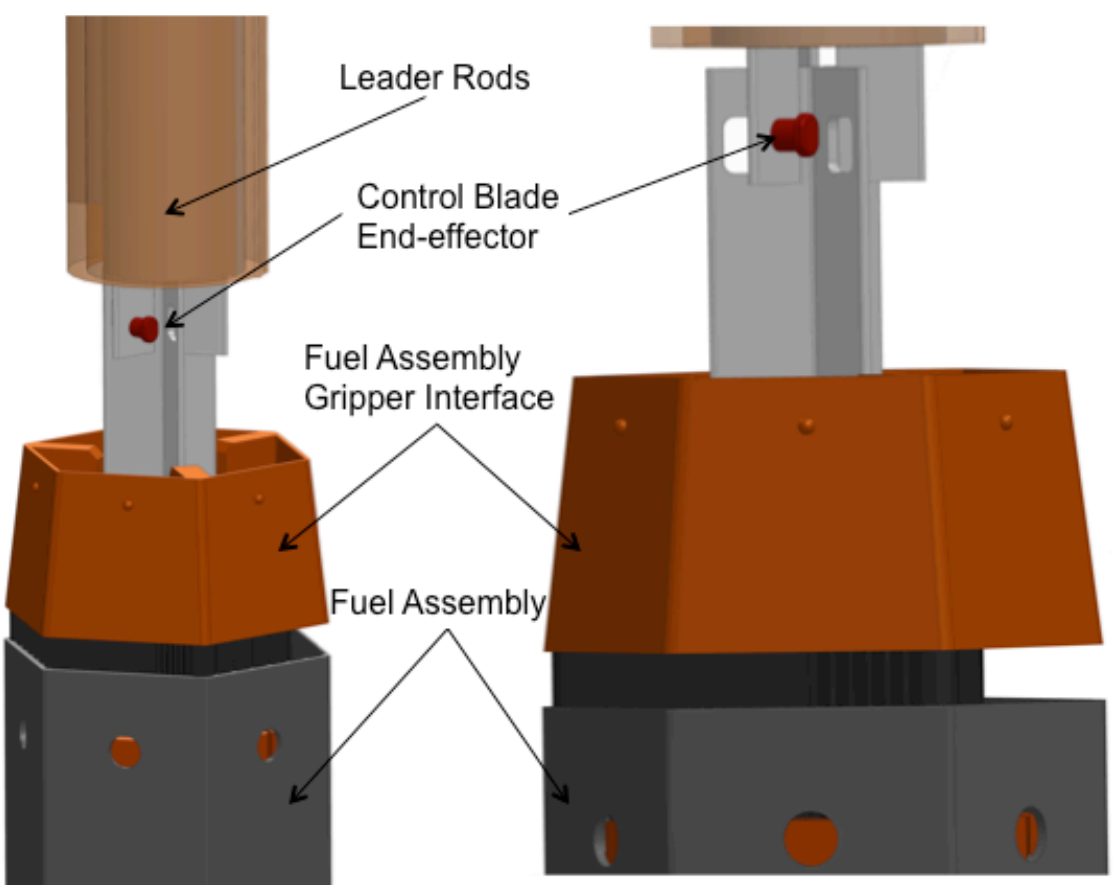

Fig. 5. Control blade attachment to the leader rods.

\section{MECHANISMS OVERVIEW}

Three fuel-handling mechanisms interface with the reactor vessel. They work cooperatively during a refueling cycle to reduce the duration of the outage. The three manipulators are as follows and are shown in Fig. 6:

- In-Vessel Fuel Handling Manipulator (IVFHM)

- Annular Rolling Manipulator (ARM)

- Used Fuel Transfer Manipulator (UFTM) 


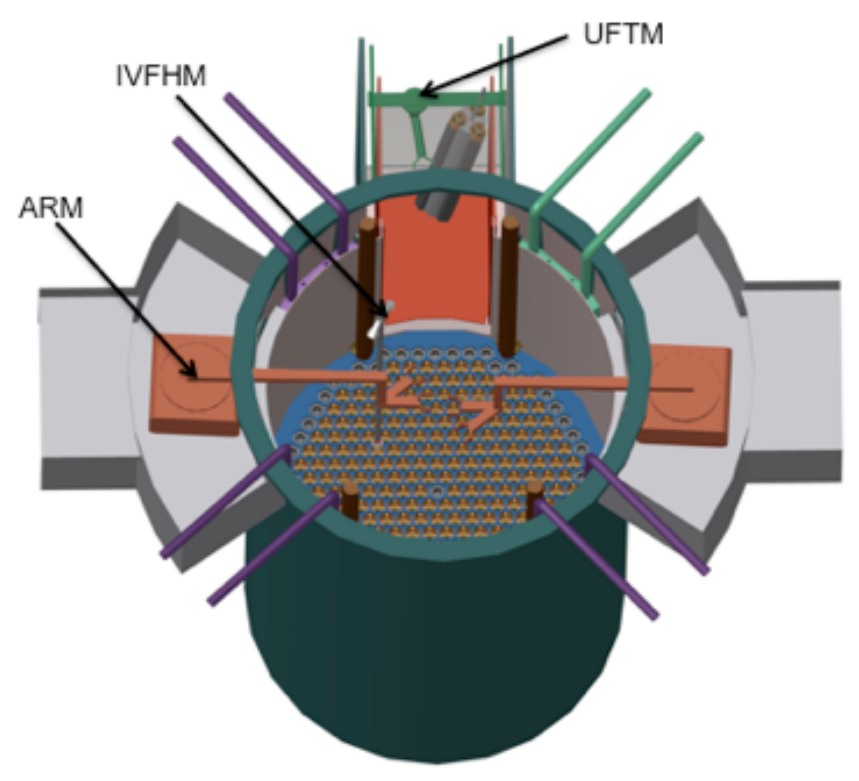

Fig. 6. Reactor top view showing all three manipulators.

\section{$5.1 \quad$ IVFHM}

The IVFHM manipulator is primarily used for vertically lifting a fuel assembly and inserting fresh fuel into the resulting empty slot in core. Two IVFHMs operate simultaneously during refueling (Fig. 7). The IVFHM has a gripper that inserts a rectangular pin into slots in the Y support plate of the fuel assembly to secure a grasp onto the fuel assembly (Fig. 8). Provisions on the gripper passively guide it both laterally and axially onto the fuel assembly. Once the gripper is correctly located, a rotary actuation on the IVFHM rod engages the pins. The lips on the pins prevent the pins from disengaging accidently during fuel transfer. Once the pins are engaged, the fuel assembly can be lifted out of the reactor core.

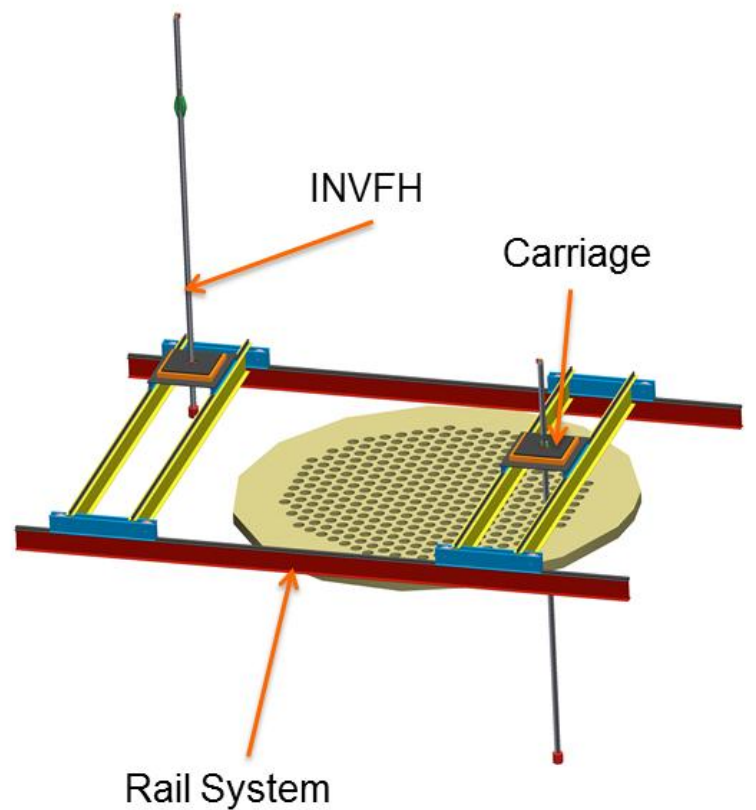

Fig. 7. IVFHM with the rail and carriage system. 

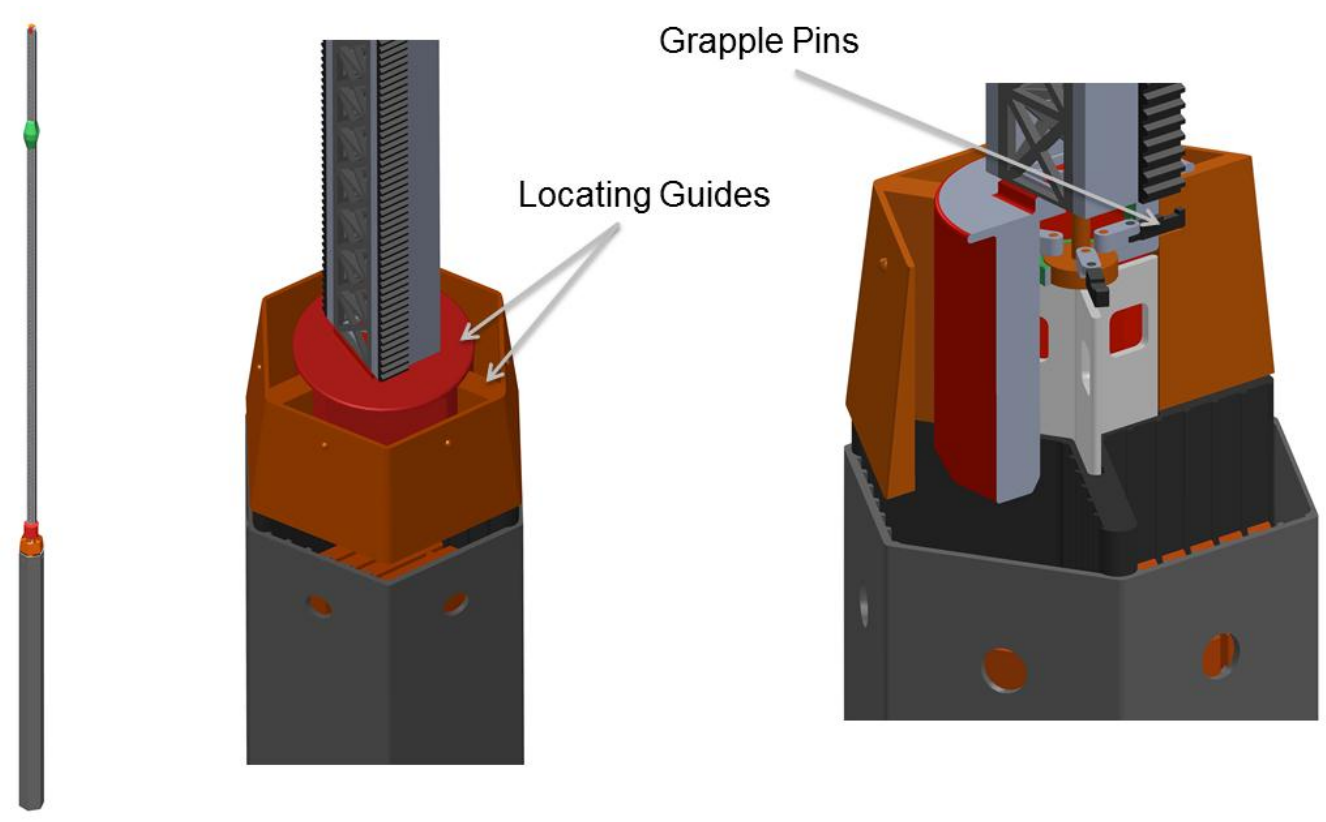

Fig. 8. IVFHM holding a fuel assembly and close-up of the grapple.

A rail on the reactor floor that runs perpendicular to the rail system for the control blade is used for mounting the IVFHMs. Each IVFHM is mounted on a carriage that runs perpendicular to the rail. This two-axis system is used to position the IVFHM over any hole location on the reactor flange corresponding to a fuel assembly. On the carriage, a compliance mechanism helps accommodate slight misalignment of the IVFHM and the fuel assembly.

Each of the two IVFHM positioning systems covers just over one-half of all the fuel assemblies. Once the fuel assemblies are lifted out, the used fuel assembly is transferred to the ARM manipulator. The new fuel assembly that is already within the other gripper of the ARM robot is then placed in the empty slot in the reactor core. This ensures that the salt flow through the empty slot does not unacceptable reduce flow through the rest of the fuel assemblies.

\subsection{ARM}

The ARM manipulator transfers the fuel from the top of the core to the refueling lobe. It has two pairs of grippers to enable replacing the used fuel assembly with a new one immediately after it has been taken out of the core (Fig. 9). The offset link enables the fuel assembly to remain immersed in the salt during transfer to the refueling lobe. The base rotary joint on this mobile manipulator allows it to reach the fuel assemblies and the refueling lobe. The wheels on the base allow the robot to translate along the arc of the ARM housing.

During normal reactor operation, the ARM robot is stowed away. To stow the ARM robot, the prismatic joints are fully retracted and the offset link pulled up from the opening in the reactor top flange and rotated to make the link horizontal. A mounting pin is then inserted into the shoulder rotary joint to hold the offset link in place. The base of the ARM is then translated radially outward from the reactor vessel to the manipulator storage area. The annular opening is then slid closed to provide containment sealing. 


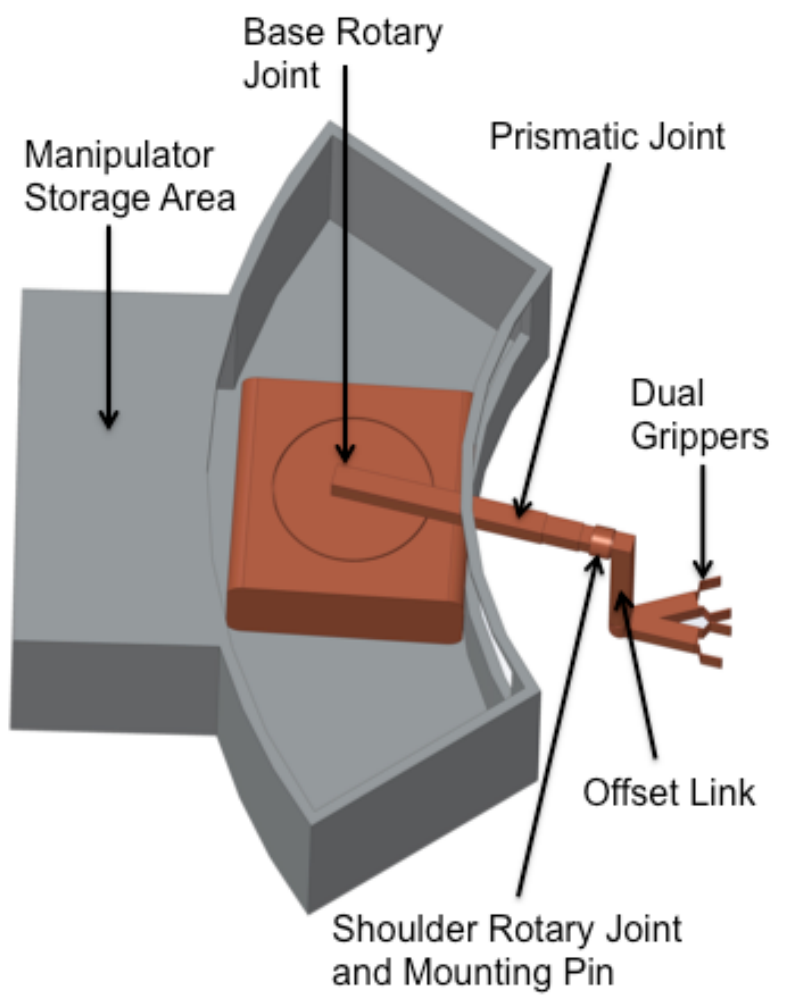

\subsection{UFTM}

Fig. 9. ARM manipulator with two grippers.

The UFTM interfaces with the ARM, the new fuel assemblies, and the used fuel assemblies (Fig. 10). The ARM brings used fuel assemblies to the refueling lobe where it transfers them to the UFTM. The UFTM places a used fuel assembly in the rotating carousel. It then picks a new fuel that is already staged on the elevator platform. The new fuel is then transferred to the ARM that brought the used fuel assembly.

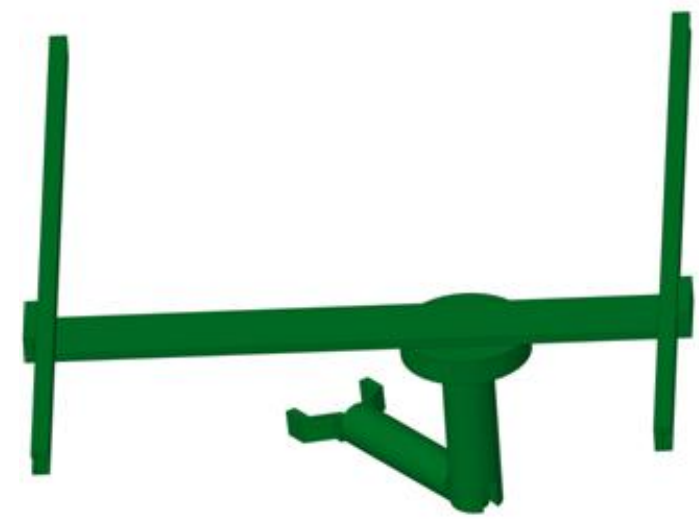

Fig. 10. UFTM.

\section{REFUELING PATH COMPONENTS AND STRUCTURES}

Figure 11 provides a conceptual overview of the fuel transfer path for removing used fuel from the AHTR. The used fuel is first transferred vertically out of the core and then translated horizontally to a fuel transfer lobe on the reactor vessel (Figs. 12 and 13). The used fuel is removed from the reactor vessel 
using a winch at a slight incline. Argon blowers are located on the slanted transfer channel to provide fuel cooling during the transfer process and to remove any primary salt that remains on the surface of the fuel assemblies. Once a fuel assembly has cleared to top of the weir, it swings over the used fuel channel and is lowered into the used fuel storage salt. The high-temperature tolerance of coated-particle fuel affords several minutes to transfer the fuel from the reactor vessel to the used fuel storage [2]. The fuel transfer process resembles that employed by Superphenix with its incline-based transfer between pools [3]. The winch grapple includes a passive melt fuse designed such that if the transfer process is interrupted, the fuel assembly's decay heat will melt the fuse causing the fuel assembly to slide back down into the coolant salt. As with the AHTR's intermediate and Direct Reactor Auxiliary Cooling System (DRACS) cooling loops, the low-melt-point eutectic of $\mathrm{KF}-\mathrm{ZrF}_{4}$ would be a suitable salt for the used fuel storage pool.

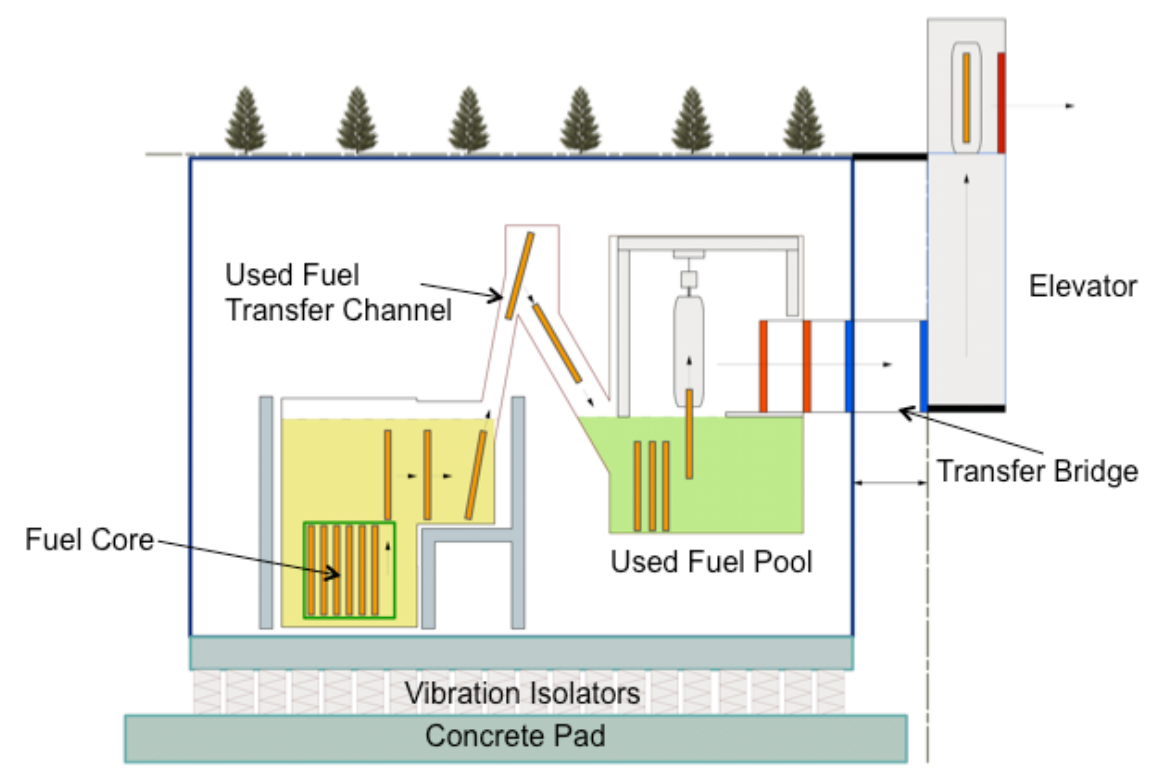

Fig. 11. Schematic of the AHTR refueling process.

Roughly 180 days following shutdown, the decay heat produced by a fuel assembly becomes less than $0.1 \%$ of its operating power $\left(<15 \mathrm{~kW} /\right.$ assembly). The AHTR core power density is $\sim 13 \mathrm{MW} / \mathrm{m}^{3}$ (about one-eighth of a LWR); thus, its fuel assemblies have a significantly lower volumetric decay heat load and can be removed from liquid cooling much sooner than an LWR assembly.

The AHTR used fuel assemblies will be maintained in an in-containment used fuel cooling pool for the next fuel cycle following removal from core (6 months) and then transferred to local dry storage using a bottom-loading used fuel cask. The used fuel storage pool is sized for storing one complete core plus a number of damaged fuel assemblies. Each half-core is intended to be stored in a single local dry well. Each well will be $\sim 800 \mathrm{~m}$ deep and $50 \mathrm{~cm}$ in diameter. The dry well will have continuous casing and cementing to prevent groundwater from infiltrating into the well. The silicon carbide containment layer within TRISO fuel is not water soluble, providing a backup radionuclide containment barrier if the well casing and cementing fail. 


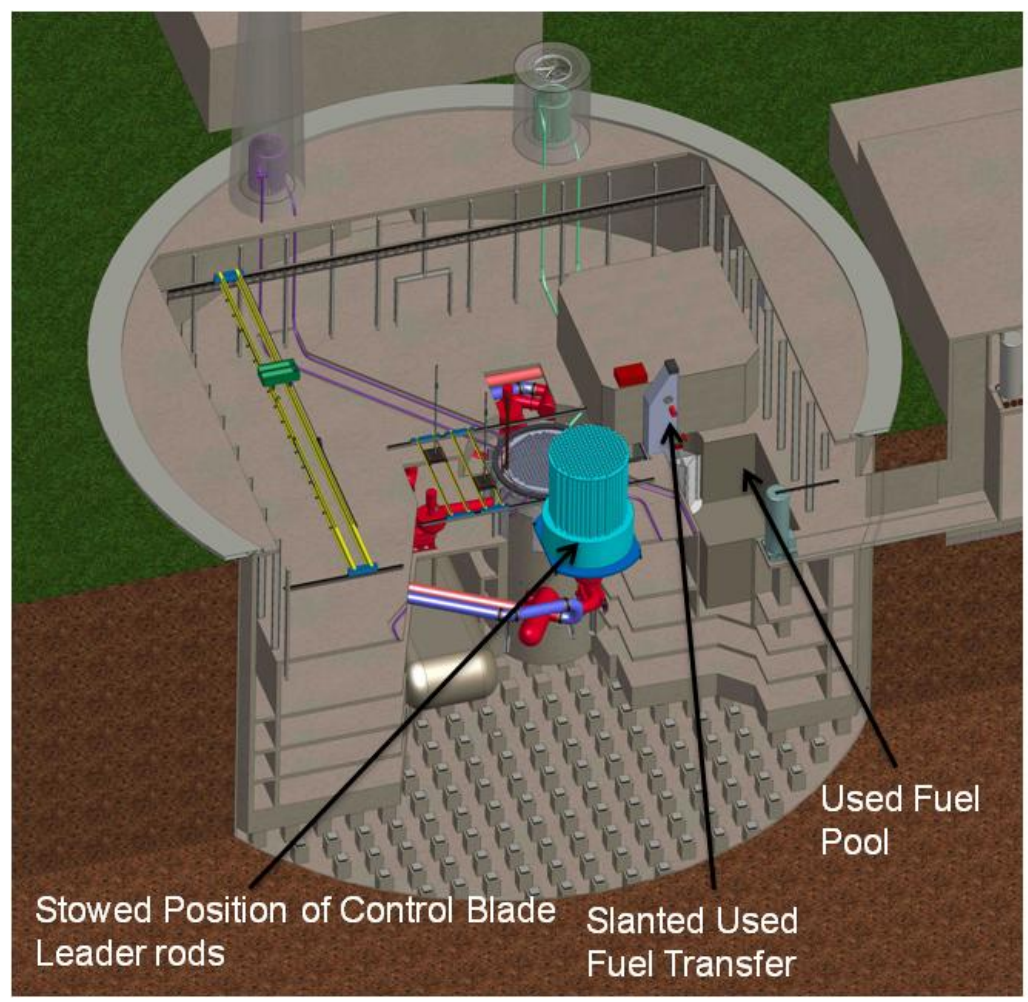

Fig. 12. Refueling and used fuel transfer.

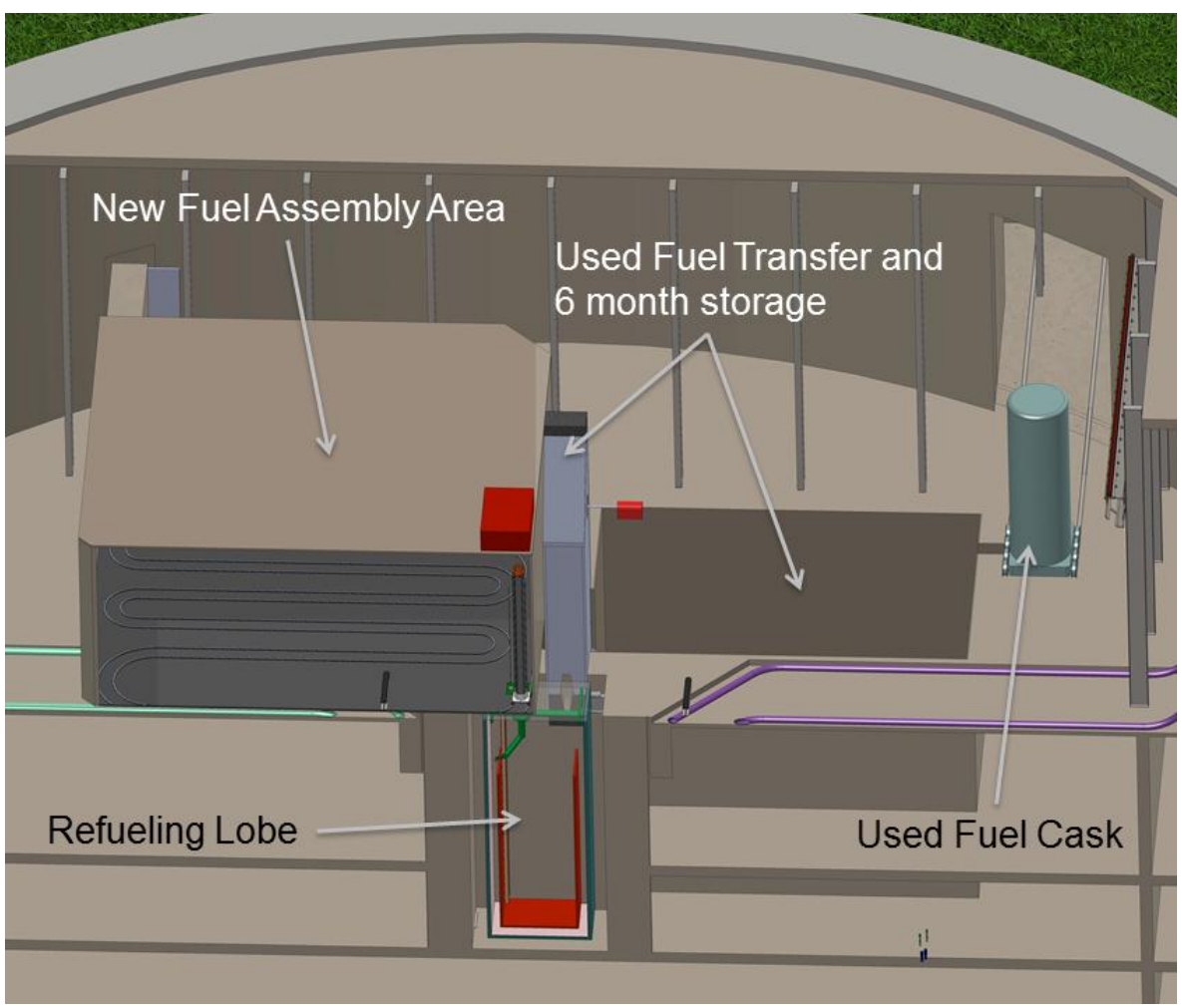

Fig. 13. New fuel loading and used fuel transfer in the reactor lobe. 


\subsection{NEW FUEL ASSEMBLIES AREA}

New fuel assemblies arrive at the reactor by rail and are manually inspected by personnel in the fuel receiving building before being transferred to the New Fuel Assembly Area (NFAA). The new fuel assemblies each enter the reactor building on its own carriage and are brought down to the reactor level by an elevator. These carriages interface with the serpentine rail system at NFAA. The NFAA includes a double-door gas interlock entrance to enable transitioning to an inert atmosphere in the NFAA. The NFAA is outside of containment and maintains an argon or dry air environment, depending on the stage of the new fuel loading process. Once all 126 assemblies are loaded, the dry air environment inside this room is flushed with dry argon. The temperature inside the building is then raised to $1000^{\circ} \mathrm{C}$ to remove entrapped moisture within the graphite fuel elements that may contaminate the salt. After maintaining the temperature at $1000^{\circ} \mathrm{C}$ for a few days, the temperature is decreased to $650^{\circ} \mathrm{C}$. The fuel is now ready for insertion into the salt. Since nearly 6 months elapses between new fuel introductions, ample time is available for the preparatory actions.

The serpentine rail system has a built-in platform for lowering fuel assemblies into the refueling lobe (Fig. 14). The platform is lowered and raised by a cable and pulley system inside the NFAA. The platform also has a sealed surface that seals the opening for maintaining a vacuum inside the NFAA. The upward force for sealing is provided by the cable drive mechanism. The platform is lowered and raised using guide rails that are permanently attached to the inside of the refueling lobe. A sealing surface on the loading platform mates with the floor to enable creating a containment seal below the new fuel assembly area (Fig. 15).
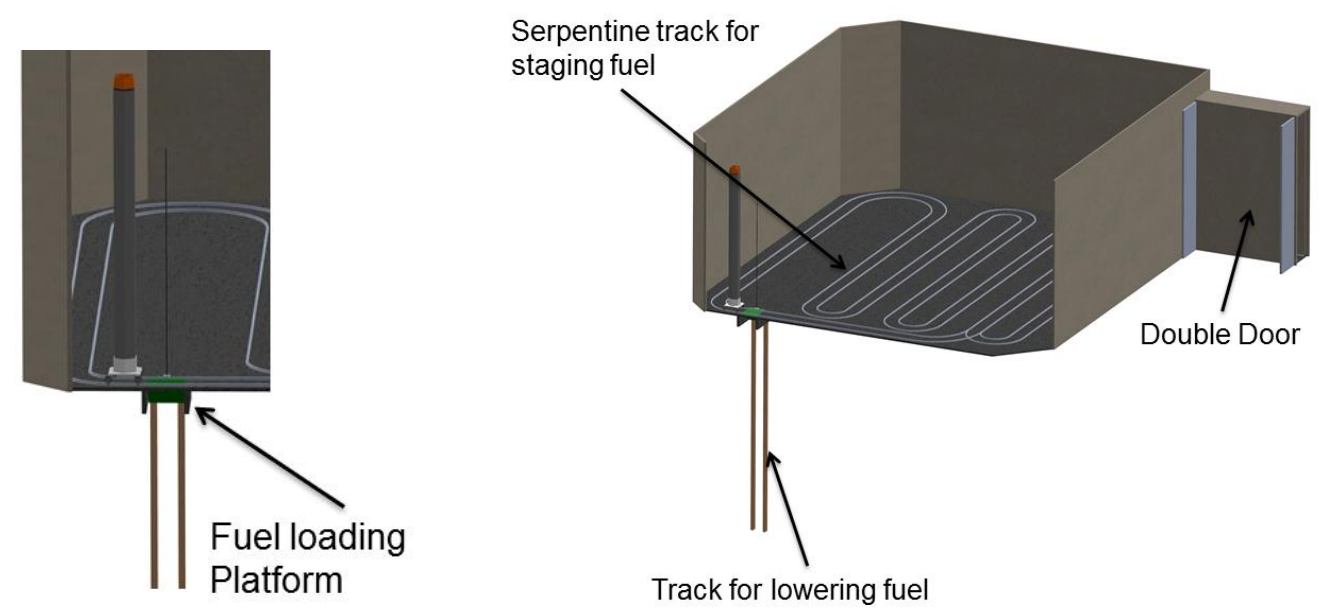

Fig. 14. New fuel assembly areas with loading platform. 


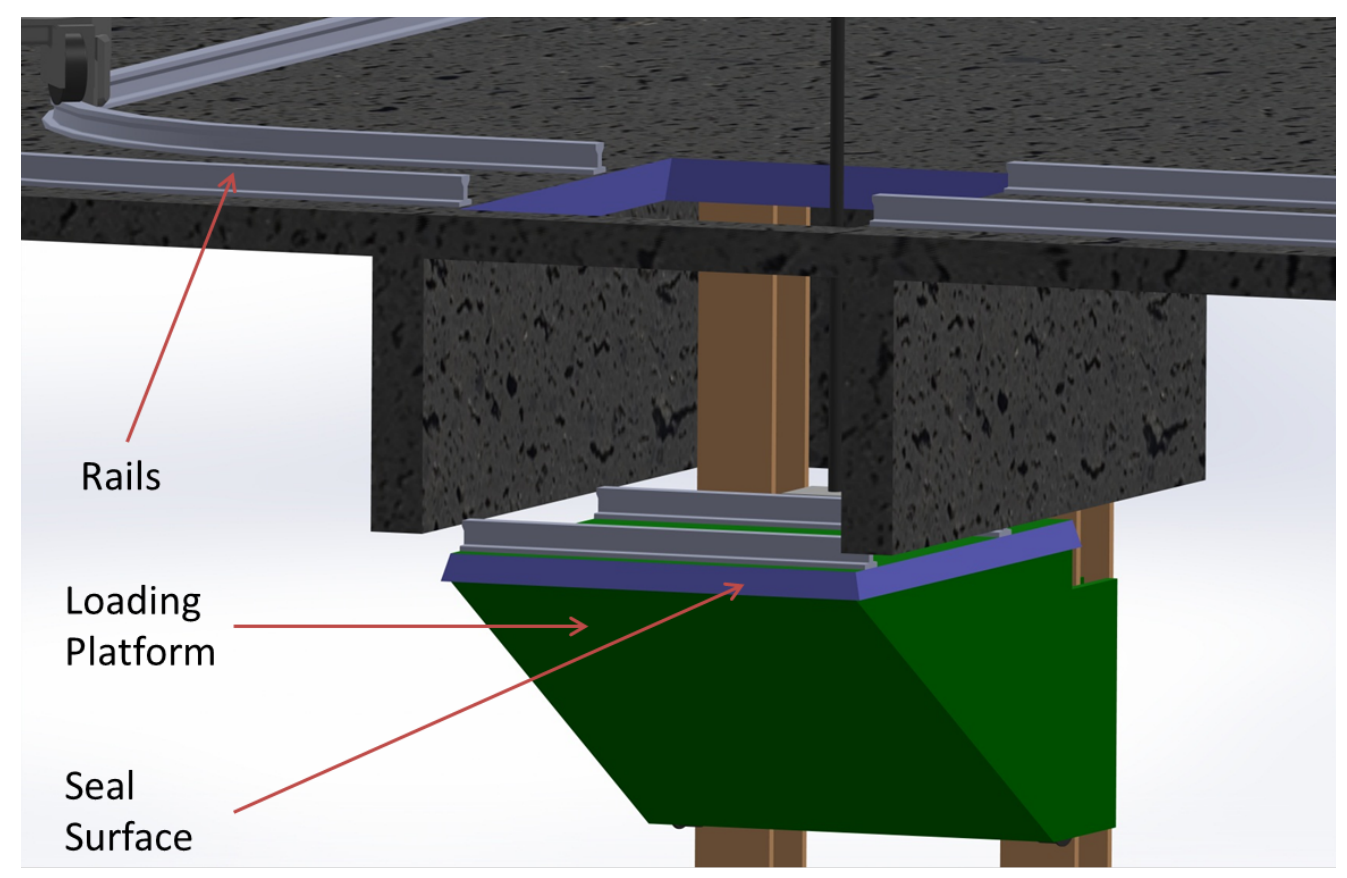

Fig. 15. Seal on the loading platform at the new fuel assembly area.

A carriage on the serpentine rail system has four support wheels. Fixed guides on the wheel assembly provide lateral support to prevent the 6-meter-long fuel assemblies from tipping while translating along the rail system (Fig. 16).

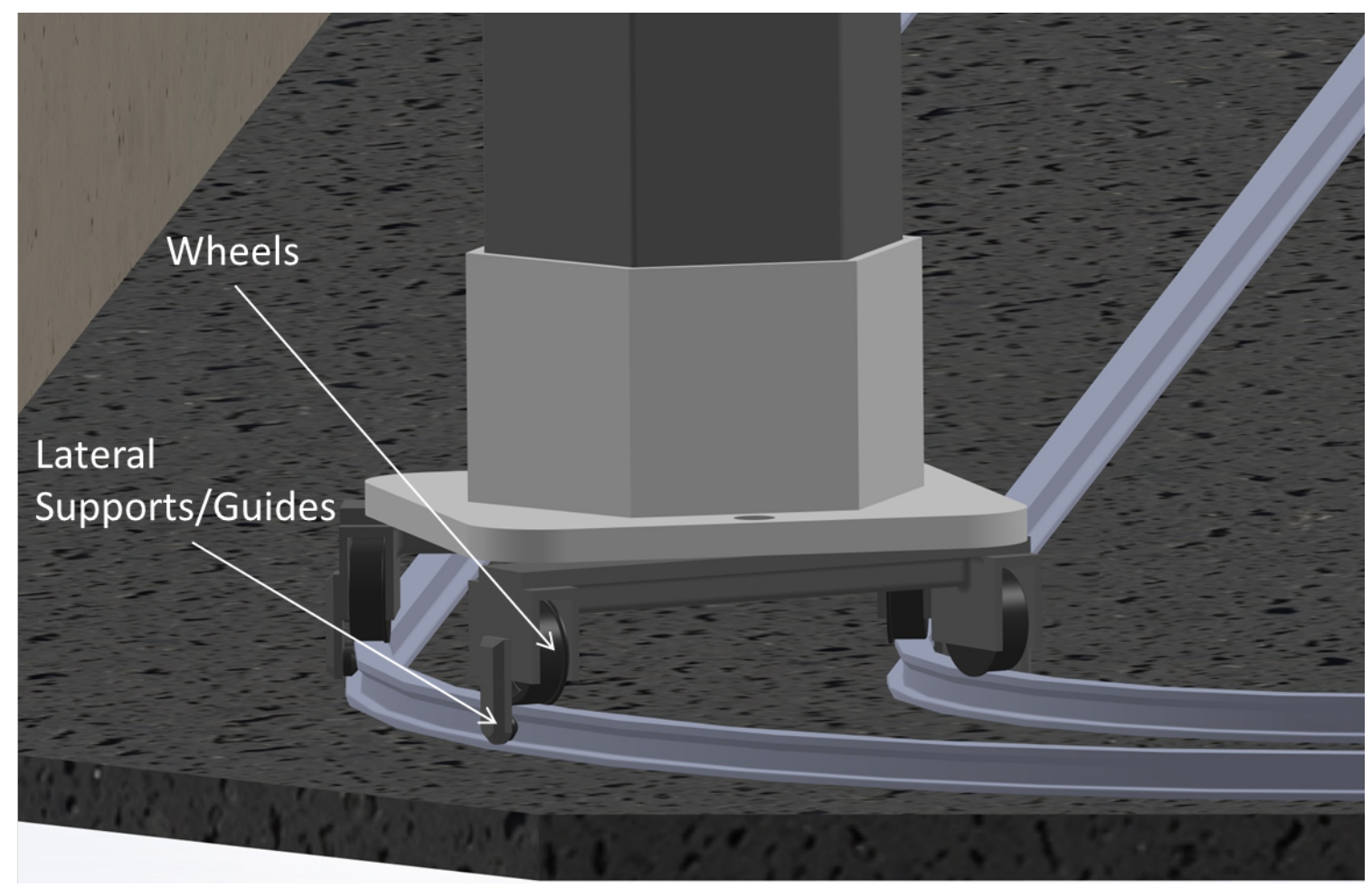

Fig. 16. Lateral guides on the fuel-handling carriage. 
New fuel assemblies that are introduced into the reactor are placed into position within the reactor core by the three manipulators described in Section 5.

\subsection{USED FUEL TRANSFER WEIR}

The used fuel transfer weir is shown in Fig. 17. The grapple mechanism used by the gripper is similar to the one employed by the IVFHM. Figure 18 shows the grapple attachment to the fuel assembly. Unlike the rotary actuation for the IVFHM, this gripper employs a spring. Once the grapple secures a grasp on the fuel assembly, the hoist pulls the fuel assembly out of the refueling lobe.

The location of the pivot point on the hoist automatically aligns the fuel assembly to the used fuel pool. Argon blowers are located on the slanted transfer channel to provide fuel cooling during the transfer process and to remove any primary salt that remains on the surface of the fuel assemblies. A gate valve is provided to isolate the salt in the used fuel pool and the refueling lobe. A fusible link on the grapple ensures that in the event that the fuel assembly motion is delayed while outside the salt, the fuel will be released to slide gently into the salt where it will remain below fuel damage temperature.

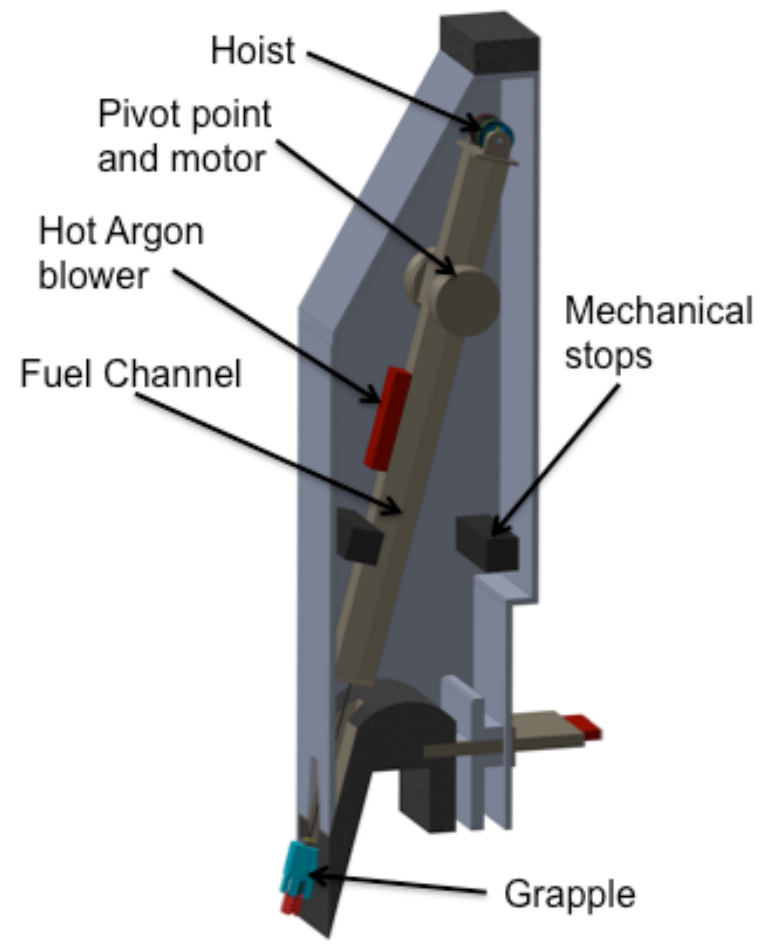

Fig. 17. Used fuel transfer weir. 

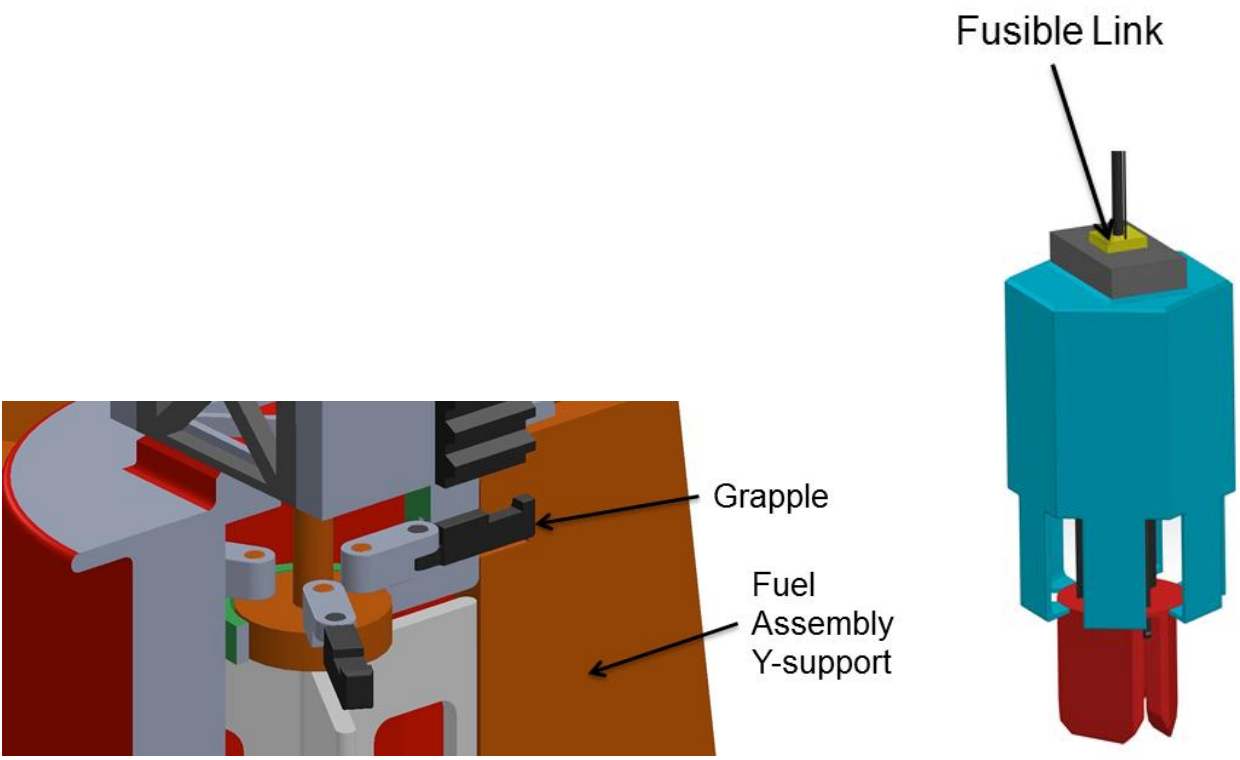

Fig. 18. Grapple attachment to the fuel assembly.

\subsection{REFUELING LOBE}

The refueling lobe is where the new fuel is staged before it is transferred to the reactor core and also the where used fuel is placed before it is transferred to the used fuel storage pool (Fig. 19). The refueling lobe houses the UFTM that interfaces with the ARM and the new and used fuel transfer mechanisms. Two meters of salt level is maintained above the fuel assemblies (except when they are lifted from the salt) to minimize the radiation levels above the salt. The $\mathrm{C}-\mathrm{C}$ core barrel continues into the refueling lobe to maintain the walls of the reactor vessel in this region at lower temperature $\left(650^{\circ} \mathrm{C}\right)$ due to bypass flow outside of the core barrel.

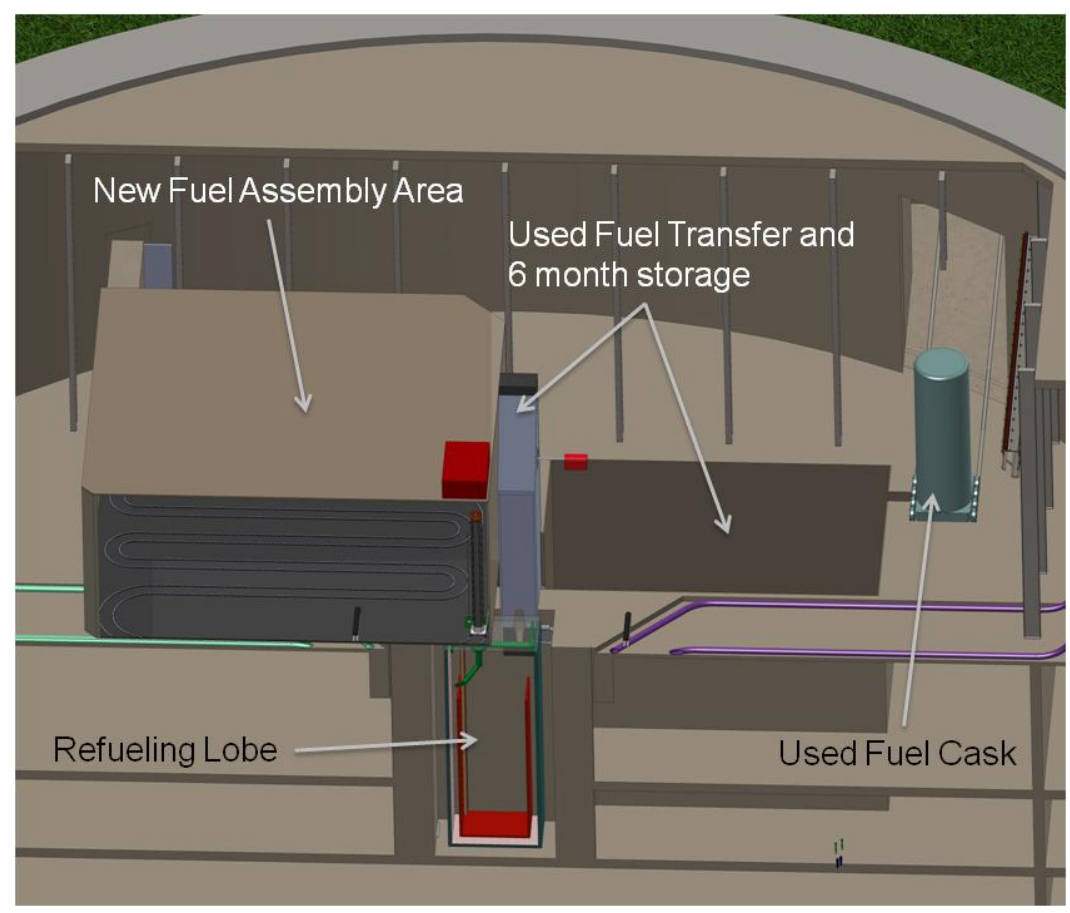

Fig. 19. Refueling lobe and its interfaces. 


\subsection{USED FUEL STORAGE POOL}

The used fuel storage pool has the capacity to hold 252 fuel assemblies, with some excess capacity to hold any damaged fuel assemblies. The salt in the used fuel storage pool is $\mathrm{KF}^{-} \mathrm{ZrF}_{4}$. During each outage, 126 new used fuel assemblies are added to the storage pool. The salt in the pool is maintained at around $500^{\circ} \mathrm{C}$. The used fuel pool will be cooled under normal operation by a maintenance cooling system. The system will also have redundant natural draft passive cooling system to account for loss-of-active-cooling accident scenarios. The design intent is to maintain a sufficient temperature margin in the used fuel storage pool such that in the event of a loss-of-forced-cooling accident, the natural draft cooling systems will prevent the pool from boiling $\left(>1400^{\circ} \mathrm{C}\right)$ or fuel damage $\left(>1600^{\circ} \mathrm{C}\right)$.

Between outages, the used fuel assemblies that have been in storage for more than 6 months are removed from the used fuel storage pool. A bottom-loading cask is used to remove these radioactive fuel assemblies from the reactor.

\subsection{USED FUEL ELEVATOR}

The used fuel assemblies have to be removed from the pool to make room for newer used fuel assemblies coming from the reactor. Since the reactor is designed to be an underground facility, the used fuel casks are lifted using an elevator (Fig. 20). The casks leave the reactor through a rail system that bridges the 1meter seismic isolation gap between the reactor and the outside. The rail system that connects the used fuel storage pool and the elevator is retractable and not a permanent structure.

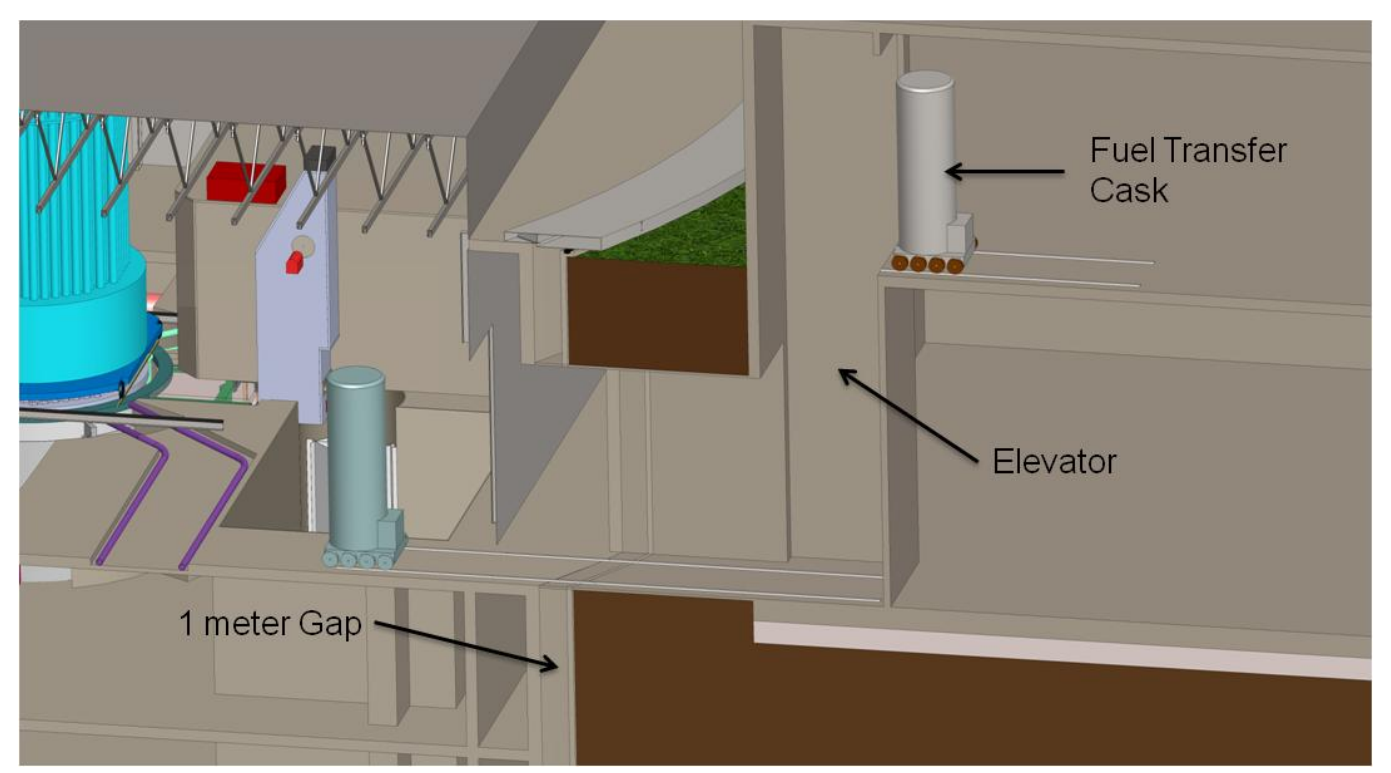

Fig. 20. Transfer cask and used fuel elevator. 


\section{REFUELING SEQUENCE OF OPERATIONS}

Every 6 months, 126 fuel assemblies are replaced with new fuel assemblies. The new fuel assemblies are loaded into the refueling lobe.

Refueling the AHTR involves the following major steps:

1. All control blades are inserted into the fuel assemblies. Control blades are detached from the leader rods.

2. The control blade leader rods and guide tubes are retracted from the reactor vessel.

3. The control blade flange with all the control blade drive mechanisms is translated laterally to provide a clear access to the top flange (Fig. 12).

4. The ARM robot is positioned so that it is over the downcomer area and does not hinder the raising of the upper core support plate.

5. The primary coolant loop pump flow is reduced to about $5 \%$, or the maintenance cooling system is brought on-line (forced convection).

6. The upper core support plate is raised until it rests below the reactor top flange (Fig. 21).

7. The IVFHM is inserted in the region where the fuel assemblies are to be removed.

8. The IVFHM is lowered over the fuel assembly and grapples the fuel assembly. The design of the grapple allows for visual verification of the grasp (Fig. 8).

9. The fuel assembly is lifted out of the core, where it is within the reach of the ARM robot.

10. The ARM robot already has a new fuel assembly at one of its grapple. The ARM secures the used fuel assembly on its other grapple while it is still held by the IVFHM.

11. A mechanical actuation on the ARM provides visual confirmation about the integrity of the grasp.

12. The IVFHM releases the grasp on the used fuel assembly and translates upward about 0.5 meters. The ARM rotates the end-effector and indexes the grapple with the new fuel under the IVFHM. The IVFHM secures the grasp on the new assembly while the ARM is still holding it (Fig. 22).

13. The IVFHM lowers the new fuel assembly and positions it on the bottom support plate.

14. The ARM moves the assembly to the used fuel transfer area.

15. The UFTM grasps the fuel assembly while the ARM is still holding it.

16. Again, a mechanical visual cue is used to ensure that the grasp by the UFTM is secure before the ARM releases the fuel assembly.

17. The used fuel assembly is then placed onto a carousel at the used fuel transfer area. A separate winch mechanism grasps the used fuel and transfers it to the used fuel transfer canal on its way to longerterm storage pool.

18. The UFTM grasps a new fuel assembly from the new fuel carousel. A new fuel assembly is loaded onto the salt pool every time the UFTM grasps the new fuel already in the used fuel transfer area. 


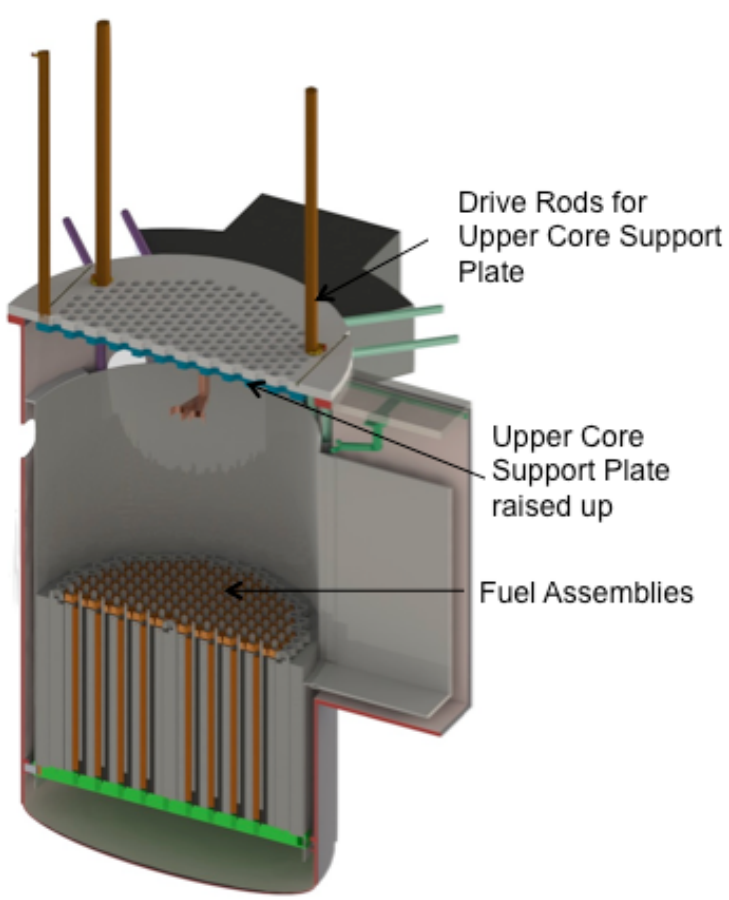

Fig. 21. Upper core support plate is raised, allowing access to the fuel assemblies for refueling.

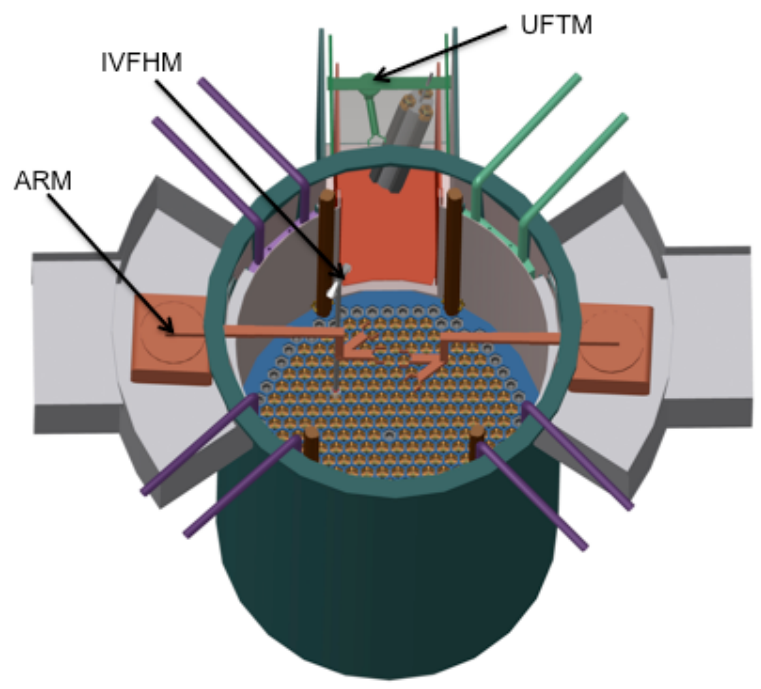

Fig. 22. IVFHM, ARM, and UFTM inside the reactor vessel.

Overall, fuel reloading is an optically guided, mechanical transfer process. Fuel movement is a critical path item for restarting the reactor, and as such, a fully automated system is being developed to maximize transfer speed. The largest challenge to the transfer system design is the requirement to keep all of the sensors and electronics in cooled regions above the salt surface. The mechanical elements grasping the fuel are roughly 10 meters long, increasing the required directional precision of the mechanical elements. However, the fuel assemblies are intended to reduce the required machine precision by use of mating elements that have self-aligning features. 
The area above the reactor vessel upper flange is both inert and contaminated with both $\mathrm{BeF}_{2}$ and tritium. As such, it is intended that fuel handling be entirely automated. The plant operators will thus be in an oversight supervisory role with a primary responsibility to respond to machine or instrument failures or incorrect operation (i.e., ensuring that the system actually replaces the fuel assemblies intended during the current outage). The fuel is transferred between different manipulators inside the reactor vessel. During each such transfer, once a secure grasp is obtained, the system will wait for the operator input to proceed to the next step. This ensures a verification of the integrity of the grasp during every critical fuel assembly transfer.

While plant staff can enter containment with proper protective equipment to perform major or unanticipated maintenance actions, they do not enter the containment during a normal refueling outage. The refueling mechanisms are planned to be retracted out of the containment boundary for anticipated maintenance procedures.

While the reactor is operating, the vessel interior temperature will be $\sim 650^{\circ} \mathrm{C}$ and the core temperature above $700^{\circ} \mathrm{C}$. The combination of the Cerenkov light emission and the thermal emission is anticipated to provide adequate lighting for power imaging. However, during refueling additional lighting will likely be required. The current design concept is to illuminate the vessel interior using relay optics that also provides optical access for the cameras. This lighting will be at the outer rim of the top cover flange.

Removing the in-vessel, fuel hold-down mechanical structures also provides improved optical access to the fuel that is not being replaced during an outage. While sufficient information about the anticipated mechanical changes to fuel assemblies during operation is not currently available, if necessary, imaging systems can be placed within the control blade holes in the control blade flange (Fig. 23) and used to observe the mechanical condition of the fuel assemblies that remain in the core.

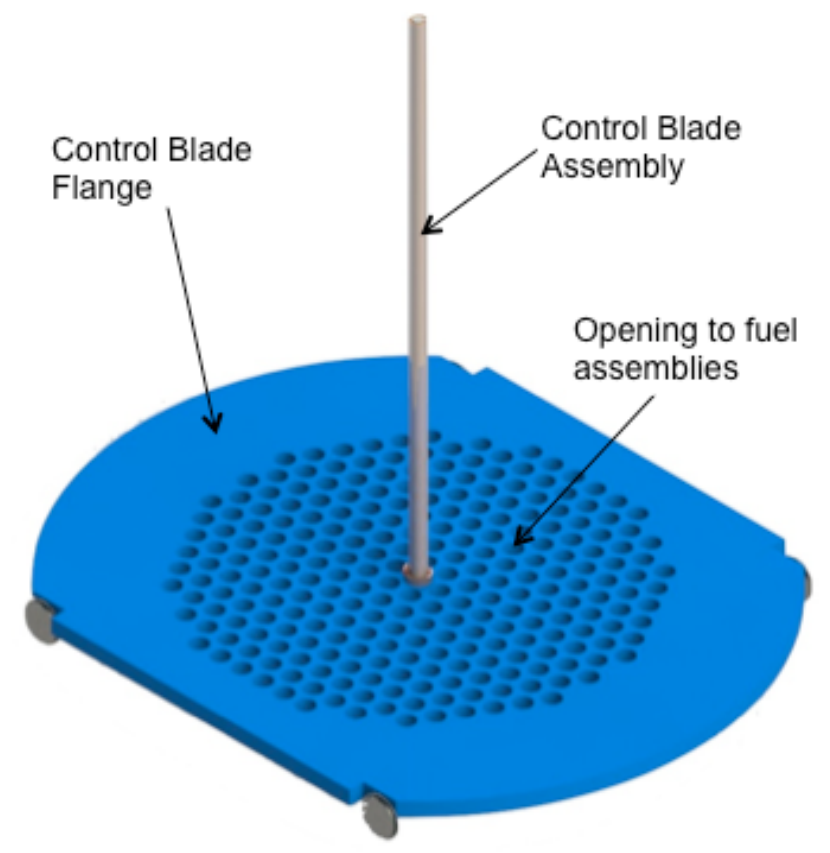

Fig. 23. Control blade flange with a single control blade drive mechanism retracted. 


\subsection{INSTRUMENTATION DESCRIPTION}

The primary salt is transparent. All of the grasping and positioning actions can be confirmed visually provided optical access is available above the pool, and cameras are provided at the proper locations. Views of the vessel interior will be provided to both the operators and the control system via relay lenses located around the periphery of the top cover flange. The optical system design concept is at a very early phase. As such, only a conceptual outline is currently available.

It is also desirable to observe the narrow coolant flow channels within the core during operation. The Cerenkov light emerging from between the fuel plates will be indicative of the local power generation. Observing the core from above also allows the degree of mechanical warping of the fuel to be observed. Consequently, additional relay lens systems will also be aligned directly above the core in the control blade flange to allow observation into the fuel channels. Additionally, since the upper core elements have high emissivity, their thermal glow will be indicative of the local coolant temperature, avoiding the need for wired temperature measurement. Overall, the camera systems will be key to refueling and beneficial to power operations.

Observing the refueling process requires overcoming several design challenges.

1. The interior surface of the top cover flange and control blade flange are at elevated temperature. While the flange temperature will be lower than that of the salt due to argon flow in the region above the pool, the optical elements within the flange will need to accommodate elevated temperatures. The current phase of the design envisions only relay lenses in the top flange with cameras located above the vessel in a controlled environment.

2. Optical alignment will change as the core expands and contracts with temperature. Cameras will have to automatically reposition to accommodate changes in the location of the relay lens.

3. The salt surface will include ripples as the salt flows. The rippling will need to be removed computationally to enable accurate imaging of the components.

4. $\mathrm{BeF}_{2}$ will evaporate from the salt surface and deposit as a polycrystalline film on cool surfaces, rapidly clouding lenses. The first surface lenses will need to be either heated, mechanically cleaned, or otherwise protected from condensation.

Apart from the optical system, the other sensor system required in the motion system will be limit switches employed as backup sensors for the handling mechanisms while positioning over the fuel assembly. Flux measurement sensors will be incorporated into a limited number of core positions. The electrical signals from these sensors will be routed along a cable tray accompanying the control blade flange. All drive motors will incorporate torque measurements to prevent inadvertent accidental breakage or failure. When the motors are experiencing greater-than-anticipated torque, the work will be stopped to investigate the issue under human supervision.

\subsection{CONTROLS DESCRIPTION}

The control system converts the desired refueling sequence into a series of machine actions, sends out the required signals to energize the drive motors, and receives feedback from the vision system that the motions are occurring as planned. The major design challenge for the control system will be to convert the input from the set of in-vessel cameras into instructions to the motor drives. The image analysis technology for vision-based control systems, however, is becoming commonplace. Consequently, it is not anticipated that developing the necessary feedback control algorithms will require significant 
advancement in the state-of-the-art. The control system will also employ power signature analysis on motor drive signals as an indication of proper performance. As much as possible, mechanical self-aligning features are incorporated into every gripper design. Visual cues are provided for a human in the loop to verify that the desired actions are being executed.

The operators need to maintain situational awareness in order to be able to respond to system malfunctions. As monitoring multiple cameras with multiple different partial views of the refueling process would be complex and confusing, a virtual reality reconstruction of the in-vessel process will need to be provided to improve the ability of the operators to oversee the interrelated series of refueling motions. The virtual reality representation of the fuel motion can also be used in advance to allow plant staff to confirm that the planned control moves match the refueling plan. Since the robots are moving in a structured environment, a robot's current position can be superimposed on a virtual image of the reactor, indicating the robot's desired final location. This process will enable verifying the trajectory taken by the robot and taking any needed corrective actions.

\section{TECHNICAL MATURITY EVALUATION}

The AHTR refueling process is a mechanical transfer process performed using remote-handling equipment performed under adverse environmental conditions. All of the individual mechanical processes involved employ well-known technology. However, the instrumentation system, the virtual reality process visualization to enable the operators to maintain process awareness, and the salt wetted materials are at lower technology readiness levels. Further, the overall refueling system design is not yet mature enough to have high confidence in any particular component or step. Details such as the dynamic loads on the fuel assemblies and thus the transfer mechanisms due to the coolant flows have not yet been established. Additionally, as the refueling operation involves a series of interrelated steps, the overall system design will require validation.

The overall refueling system concept development remains too immature to enable selection of particular components. Significant instrumentation, controls, and human-machine interface elements remain to be developed. The most significant instrument component development required to enable the intended optically guided process is the set of telescope optics necessary to observe the mechanical processes. The leading controls challenge for the refueling process is implementing the vision-based feedback into the control algorithm. The design intent is for the plant operators to have an oversight role in the fuel transfer process and be able to override any system actions if incorrect function is observed. In order to allow the operators to maintain situational awareness, a virtual reality-type display of the fuel motion will also need to be developed.

While several required materials (e.g., SiC-SiC composites and $\mathrm{Au}$-Sn thermal release fuses) are not yet mature enough to be employed in the refueling system, the environmental conditions during refueling are less challenging than during power operation. Thus, most of the materials development efforts should focus on materials performance under operating and accident conditions rather than refueling.

\section{SUMMARY AND RECOMMENDATIONS FOR FUTURE DEVELOPMENTS}

The AHTR refueling system preconceptual design is now complete, and a workable approach to refueling the reactor has been developed. As some of the underlying technologies are not yet mature enough to proceed to more detailed concept development, progress in the AHTR refueling system development will now be dictated by technology developments, primarily in instrumentation, controls, and human-machine interface technology. 
Reactor physics requires that volumetric fuel loading of any graphite-moderated reactor be lower than that of an LWR. Hence, in most cases refueling will need to occur more frequently. However, the combination of FHR properties (transparent coolant, low-pressure, large margin to boiling, very robust fuel) combine to potentially enable sufficiently rapid off-line refueling so that refueling downtime would not be a significant contributor to lowering plant availability. Plant availability is a primary determinant in the economic viability of any reactor. Developing the instrumentation and controls technologies necessary to for rapid refueling is thus a high priority within the FHR development program.

The next recommended development step is to create a computer-based model of the refueling system interacting with the instrumentation and controls. As the overall refueling system is complex, augmenting the computer-based modeling with progressively more realistic physical mock-ups will provide higher confidence in proper refueling system operation. A scaled, surrogate material mock-up, followed by a more detailed nontoxic fluoride salt in an inert atmosphere demonstration, is recommended. The vision system will need to be eventually demonstrated above a FLiBe pool as the system design matures as $\mathrm{BeF}_{2}$ may have different deposition properties. However, $\mathrm{ZrF}_{4}$ also has a high vapor pressure at low temperature and can serve as the nontoxic surrogate for initial testing.

\section{REFERENCES}

1. D. E. Holcomb, D. Ilas, A. L. Qualls, F. J. Peretz, V. K. Varma, E. C. Bradley, and A. T. Cisneros, "Current Status of the Advanced High Temperature Reactor," Paper 12342 in Proceedings of ICAPP 2012, Chicago, IL, June 24-28, 2012.

2. D. E. Holcomb, D. Ilas, V. K. Varma, A. T. Cisneros, R. P. Kelly, and J. C. Gehin, Core and Refueling Design Studies for the Advanced High Temperature Reactor, ORNL/TM-2011/365 (September 2011).

3. Y. Chikazawa, M. Farmer, and C. Grandy, "Technology Gap Analysis on Sodium-Cooled Reactor Fuel-Handling System Supporting Advanced Burner Reactor Development," Nuclear_Technology, 165, 270-292 (March 2009). 